\title{
EREBEA
}

Revista de Humanidades

y Ciencias Sociales

NúM. 3 (2013), pp. 293-327

ISSN: 0214-0691

\section{El INGENiERo Luis de MoNTALbÁN y LA FORTIFICACión DE LA COSTA ATLÁNTICA DE ANDALUCía EN El SIgLO XVI}

\author{
Domingo Muñoz Bort \\ Universidad de Huelva
}

Resumen

El estado de la historiografía sobre la construcción del sistema defensivo costero atlántico de Andalucía es hoy día muy completo, pero quedaban algunas dudas, entre otras, sobre ciertos actores de aquel proyecto tan importante para Felipe II, como es el caso del ingeniero Luis de Montalbán. Este estudio expone la relación y participación de Luis de Montalbán en la edificación de aquellas torres vigías en la costa occidental andaluza, con todos los detalles que la documentación inédita que aportamos ha permitido mostrar. A modo de una breve biografía, hemos recorrido todos los avatares por los que atravesó este personaje desde su llegada a estas costas en 1586 y como rematista de la mitad de las torres previstas, principalmente en el Espacio Natural de Doñana.

\section{Palabras Clave}

Torres vigías. Almenaras. Defensa costera. Corsarios. Costa de Andalucía. Huelva. Dońana. Almonte. Felipe II. Medina Sidonia. Luis de Montalbán.

Fecha de recepción: 28 de junio de 2013

Fecha de aceptación: 31 de julio de 2013

\section{Abstract}

At present the historiography of the building of the Atlantic coastal defence system of Andalusia is largely complete, but some doubts remain, among them those related to certain actors in this important project for Philip II, as in the case of the engineer Luis de Montalban. This study describes, with all the details of the unpublished documentation provided here, the role of Luis de Montalban in the process of building those watchtowers on the west coast of Andalusia. By way of a brief biography, we have gone through all the vicissitudes Montalban experienced from his arrival on these shores in 1586, as the engineer to finish half of the towers planned, mainly in the Doñana Natural Area.

\section{KeYwords}

Watchtowers. Beacons. Costal defense. Corsairs. The Andalusian Coast. Huelva. Doñana. Almonte. Philip II. Medina Sidonia. Luis de Montalbán. 



\section{INTRODUCCIÓN}

La abundante bibliografía existente sobre la dotación de un sistema defensivo y de alerta en las costas españolas durante la Monarquía Hispánica en el Mediterráneo y Golfo de Cádiz refleja hoy un buen conocimiento de sus principales facetas, especialmente las defensas levantadas en el estrecho de Gibraltar, Cádiz y su entorno portuario, por su proximidad a las bases turcoberberíscas norteafricanas y al pujante comercio colonial americano y europeo de la segunda mitad del Quinientos.

A los trabajos de investigación pioneros de Sancho de Sopranis, Fernández Cano, Calderón Quijano y Mora-Figueroa ${ }^{1}$ sobre las costas de Andalucía, le siguieron en profundidad los estudios de Cámara Muñoz, Sáez Rodríguez y, para el litoral onubense, el trabajo común de Villegas Martín, Mira Toscano y Carriazo Rubio ${ }^{2}$. Este último trabajo repasa todos los acontecimientos ocurridos desde la visita a este litoral de Luis Bravo de Lagunas en 1577, los múltiples inconvenientes para la construcción efectiva de las torres vigías, el impulso que supuso la estancia del nuevo comisionado real Gilberto de Bedoya y sus realizaciones concretas, con documentación inédita, el estado de las obras ejecutadas asimismo hacia el año de 1618, con todos los pormenores económicos de su financiación, sobrepasan incluso el marco geográfico objeto de su estudio.

La defensa y vigilancia del tramo atlántico de la costa andaluza era una necesidad prioritaria en la política exterior de Felipe II, especialmente preocupante tras el fracaso de la "Armada Invencible", que quiso poner coto a los desmanes de las flotillas inglesas en nuestras costas. El investigador L. Salas Almela así nos lo expone:

1 H. Sancho de Sopranis, "El viaje de Luis Bravo de Laguna y su proyecto de fortificación de las costas occidentales de Andalucía de Gibraltar a Ayamonte", Archivo del Instituto de Estudios Africanos, 42, Madrid, 1957, pp. 23-78. V. Fernández Cano, Las defensas de Cádiz en la Edad Moderna, Sevilla, 1973. J. A. Calderón Quijano, Las defensas del Golfo de Cádiz en la Edad Moderna. Discurso en la R. A. de Bellas Artes de Santa Isabel de Hungría. Sevilla, 1974. L. DE Mora-Figueroa, Torres de almenara de la costa de Huelva. Huelva: Diputación, 1981.

2 A. Cámara Muñoz, "Las torres del litoral en el reinado de Felipe II: una arquitectura para la defensa del territorio (I)", en Espacio, tiempo y forma. Serie VII, Historia del Arte, no 3 (1990), pp. 55-86. A. J. Sáez Rodríguez, Almenaras en el Estrecho de Gibraltar. Las torres de la costa de la Comandancia General del Campo de Gibraltar, Instituto de Estudios Campogibraltareños, Algeciras (2000). J. Villegas Martín, A. Mira Toscano y J. L. Carriazo Rubio, "Nuevas aportaciones para la historia de las torres de almenara onubenses", en Huelva en su historia, no 12, Huelva (2005), pp. 99-129. 
Además, la coyuntura bélica sufrió una inmediata inversión temporal, al quedar la iniciativa militar en el Altántico en manos inglesas: de los planes de ataque se pasó a la urgencia de la defensa costera peninsular a partir de septiembre. De este modo, el viejo proyecto de las torres vigía en Andalucía recibió un nuevo y definitivo impulso, aun antes del regreso de los restos de la Gran Armada. $^{3}$

La defensa naval del Estrecho y de las costas andaluzas y del Algarve portugués, más la protección de las flotas de Las Indias corrían a cargo de las capitanías General de las Costas de Andalucía y General del Mar Océano, ambas en manos del VII duque de Medina Sidonia. Quedaba ahora prevenir y evitar los continuos saqueos de bienes y personas que sobre nuestras costas suratlánticas efectuaban los piratas norteafricanos por medio de unas torres vigías intercomunicadas, que podían también delatar la presencia de flotillas enemigas. La expresión "moros en la costa" ha quedado instalada en nuestro leguaje coloquial, pero su origen, evolución y el tremendo daño personal que estos corsarios infligieron a nuestras poblaciones costeras andaluzas no han sido aún estudiado en profundidad, salvando ciertos avances. ${ }^{4}$ Hasta las defensas e incluso la construcción de algunas de aquellas torres de vigías se vieron implicadas en tales saqueos, como sucedió con las torres del Oro $^{5}$ y Asperillo. ${ }^{6}$

En la bibliografía citada y en la documentación primaria aparece un maestro de geometría, maestro de obras, fontanero e ingeniero, que unos llaman Francisco, otros Luis, e incluso Lucas, muy ligado al diseño y a la construcción de estas torres, donde sólo coinciden en su apellido "Montalbán" o "Montalvo". La profesora Alicia Cámara Muñoz advertía en 1990 de sus dudas sobre este Francisco o Luis Montalbán y de que sea la misma persona por haberlo hallado con estos nombres en distintas fuentes:

3 L. Salas Almela, Medina Sidonia. El poder de la aristocracia. 1580-1670. Madrid, 2008, p. 232. Se basa el autor en una carta de Felipe II a Juan Pedro Livadote fechada en 9 de septiembre de 1588. A(rchivo) F(undación) C(asa) M(edina) S(idonia), leg. 2.401.

4 J. L. Gozálvez Escobar, "La piratería y la redención de cautivos en las costas de Huelva. Siglos XVI-XVIII", en Huelva en su historia, no 2, Huelva (1988), pp. 359-386. A. J. Sáez Rodríguez, "Moros en la costa", Aljaranda, no 33, Cádiz (1999), pp. 7-13. A. Mira Toscano y J. Villegas Martín, "Vigilancia y defensa del litoral. Entre el Piedras y el Odiel", en Huelva en su historia, no 10 , Huelva (2003), pp. 95-131. J. Villegas Martín y A. Mira Toscano, "Un despoblado en el marquesado de Gibraleón: el Rincón de San Antón (siglos XIII-XVII)”, en J. A. Pérez Macias et al. (Ed.): Paisajes, tiempos y memoria. Huelva, 2012, pp. 159-223.

5 Mora-Figueroa, Torres de almenara ..., op. cit., p. 34.

6 Cámara Muñoz, "Las torres del litoral en el reinado de Felipe II ..., op. cit., p. 70. Villegas Martín et al.: "Nuevas aportaciones ..., op. cit., p. 125. 
Con respecto a este Montalbán se nos plantean dudas, ya que en unos documentos se le llama Luis y en otros Francisco, pero coincide la ida de "Luis» a la corte a llevar el informe en 1576 con que a "Francisco" le nombren "maestro mayor de fuentes y encañados» en El Escorial, en cambio no coincide el que en 1581 se hable de él como residente en Sevilla con los trabajos que se atribuyen a Francisco de Montalbán en El Escorial esos años, siendo de nombre «Francisco» el «maestro mayor de edificios de agua» del rey y el que se queja de estar destinado en Andalucía a pesar de tener casa en Madrid. Hasta que nuevos documentos o datos que ahora desconozco aclaren si puede tratarse de la misma persona, consideramos necesaria esta nota aclaratoria. ${ }^{7}$

La duda planteada por esta profesora era razonable ante la simultaneidad y dispersión geográfica de algunos trabajos realizados por este afamado ingeniero real Francisco de Montalbán a lo largo de sus casi treinta años al servicio de la corona. Entre los años 1570-1589 trabaja en el Real sitio de Aranjuez ejecutando presas, diques, jardines y estanques a las órdenes de Juan de Herrera, como "experto en sistemas hidráulicos y fontanería", donde también interviene Pietre Jansen; y en los mismos ańos trabaja como "fontanero" en el Escorial, ejecutando el ingenio de instalar agua caliente. ${ }^{8}$ En 1585 Felipe II ordena a Francisco de Montalbán que proyecte y valore la traída de agua potable a Valladolid, considerándolo como uno de los mejores ingenieros hidráulicos del momento, como demostró en sus trabajos de las fuentes de la Casa de Campo en 1567. Entre 1578-1581 trabaja como maestro de obras en el proyecto de la acequia de Colmenar de Oreja, una de las obras "más notables de canales realizadas en la España del siglo XVI", donde llegaron a intervenir los mejores arquitectos e ingenieros de Felipe II: Juan Francisco Sitoni, Jerónimo Gili, Juan de Herrera, Juanelo Turriano, Mariano Azaro y Benito de Morales, entre otros. ${ }^{9} \mathrm{Y}$ en el año 1581 Francisco de Montalbán colabora con el también ingeniero Mariano Azaro en la construcción de dos dársenas circulares y un largo canal navegable próximo a la ciudad de Jerez. Un par de años antes, Francisco de Montalbán había firmado con el Ayuntamiento de Jerez un contrato para el abastecimiento de agua potable; por estas fechas también se compromete para la traída de agua potable con los gobiernos de Écija y del Puerto de Santa María. Durante los meses de septiembre a diciembre de 1586 nuestro incansable ingeniero visita las

7 Cámara Muñoz, "Las torres del litoral en el reinado de Felipe II..., op. cit., p. 68.

8 N. García Tapia, Ingeniería y arquitectura en el Renacimiento español, Valladolid, 1990, pp. 217-227.

9 Ibídem, pp. 447-450. 
costas de Andalucía como comisionado regio en las fábricas de las torres de vigía, cargo que al parecer ostentó hasta 1588 en que por enfermedad fue sustituido por Juan Pedro Livadote ${ }^{10}$. A partir de aquí, no volvemos a tener noticias de este afamado ingeniero cordobés.

En la intervención de Francisco de Montalbán en el abastecimiento de agua a Jerez descubrimos la existencia de su hermano Luis de Montalbán, maestro de obras e "ingeniero", como él mismo se intitula ante un escribano público de la villa de Almonte en 1589. ${ }^{11}$

Este breve estudio, de ribetes casi biográficos, pretende incidir en la aportación y los trabajos que este ingeniero Luis de Montalbán efectuó en el diseño y en la propia construcción de aquellas torres vigías o de almenara en la costa de Huelva, sin dejar de acudir a la situación y efectos que aquel proyecto militar supuso para la villa de Almonte, sobre cuyo término se dispuso la construcción de casi la mitad de las torres previstas en la costa de Huelva.

\section{Perfil profesional del ingeniero Luis de Montalbán.}

De su vida, familia y estudios más bien poco sabemos. De origen cordobés, estaba casado con una tal María Rodríguez y al parecer cursó estudios de geometría en Madrid; datos que irán apareciendo en el tenor de este artículo. Hemos rastreado y encontrado algunos datos sobre su quehacer profesional en este último tercio del siglo XVI. Creemos que la primera actuación profesional que como ingeniero hidráulico efectuó fue en la Sevilla del Asistente conde de Barajas, participando en la urbanización de la laguna de la Feria para convertirla en jardín público, y en el abastecimiento de agua potable mediante fuentes a varios barrios. Este proyecto hidráulico y la urbanización de aquel espacio degradado e insalubre se "convirtieron en las dos grandes piezas de la actuación urbana más amplia generada en Sevilla en la Edad Moderna". ${ }^{12}$ La idea fue alumbrada probablemente por Felipe II, amante de los jardines italianos y flamencos, en su visita a la ciudad en 1570, con los estudios y planos efectuados por el arquitecto real Juan de Herrera hacia 1573. Pero la ejecución final corrió a cargo de Francisco Zapata de Cisneros, primer conde de Barajas, durante

10 Cámara Muñoz, "Las torres del litoral en el reinado de Felipe II ..., op. cit., p. 68.

11 A(rchivo) de P(rotocolos) N(otariales) de L(a) P(alma) del C(ondado), leg. 7. Escritura de reconocimiento de deuda de Luis de Montalbán a Pedro Gutiérrez, carpintero y vecino de Sevilla. Almonte, 1589. Escribanía de Diego Dávila, fotograma 13. Advertimos en esta cita que dado que este importante archivo ha sido microfilmado por el Ayuntamiento de Almonte resulta más práctico citar el número de fotograma inicial, pues los primeros legajos, o no están foliadas sus páginas, o bien los cantos superiores derechos están tan deteriorados que su foliación original ha desaparecido. Cuando ha sido posible y fiable dicha foliación se ha citado.

12 A. J. Albaldonedo Freire, "Las trazas y construcción de las Alameda de Hércules", en Laboratorio de Arte II. Sevilla: Universidad, 1998, pp. 135-165. 
los ańos 1573 a 1579. Todo parece indicar que los trabajos prácticos fueron encomendados al ingeniero Luis de Montalbán en diciembre de 1573, quien actuó con celeridad, y en pocos meses el agua abastecía las viejas y nuevas fuentes que se levantaban, aunque las aguas de la fuente de la collación de San Vicente no llegaban con regularidad; la ciudad reclamó al ingeniero los nuevos gastos del arreglo y se entabló pleito. A pesar de estos problemas puntuales, el ingeniero Luis de Montalbán siguió ligado a la ciudad, donde tenía casa abierta, realizando visitas periódicas y reparaciones en las instalaciones hidráulicas de agua potable durante los años de 1575 a 1594.

En el año 1574 Luis de Montalbán estuvo un tiempo en Jerez, acuciada desde hacía décadas por la falta de agua potable, invitado por su gobierno municipal, estudiando la posibilidad de abastecer a dicha ciudad desde manantiales próximos, y descartó la posibilidad de un suministro eficaz desde el manantial conocido por fuente de Pedro Díaz, el más cercano a la ciudad. ${ }^{13}$ Paradójicamente, y tras quejarse Jerez y pedir auxilio al rey, el 16 de octubre de 1579 el "fontanero real" Francisco de Montalbán firma con dicho gobierno un contrato para la conducción de agua a la ciudad desde la fuente de Pedro Díaz. A primeros de marzo de 1580 llega a Jerez Luis de Montalbán y en julio de ese mismo su hermano Francisco retorna a Madrid, quedando Luis como director de los trabajos y residiendo en casa alquilada en Jerez. En esta ciudad, Luis otorga poder general para pleitos en marzo de 1580 ante la denuncia de la Corona presentada contra él por haberse equivocado en el emplazamiento de la torre vigía del Guadiaro en término de Gibraltar. ${ }^{14}$ Todo indicaba que los trabajos iban a buen ritmo aunque con retrasos en los pagos y financiación de las obras por parte del gobierno local, hasta que en 1583 los trabajos se paralizan y Luis de Montalbán abandona la ciudad. El cabildo jerezano pide rendir cuentas a Francisco Montalbán del abono efectuado de 8.000 ducados y que otorgue fianzas abonadas para finalizar las obras, o bien que devuelva el total devengado. Nada se resuelve y la ciudad se queja de estos hermanos a Felipe II, por cuya mediación regresa Francisco a la ciudad en 1585, acusándose mutuamente de la paralización de las obras. Por el año 1588 se dio por finalizado aquel proyecto interrumpido y la ciudad de Jerez volvía a buscar maestro que resolviera el problema ahora grave para esta ciudad, pues el manantial de Pedro Díaz se había secado por el año $1590 .^{15}$

En noviembre de 1587 Luis de Montalbán se encuentra en Huéscar (Granada) trabajando en un equipo formado por maestros de geometría, donde

13 M. Romero Bejarano, "El gran engaño del agua. Francisco de Montalbán y la obra del acueducto de Jerez de la Frontera, 1579-1586”. En S. Huerta, S. Martín, R. Soler y A. Zaragozá (Eds.): Actas del Sexto Congreso Nacional de Historia de la Construcción. Madrid, 2009, p. 1215.

14 Romero Bejarano, “El gran engaño del agua ..., op. cit., p. 1210. Ibídem, p. 1210.

15 Ibídem, p. 1217. 
se incluían él y Jerónimo Muñoz, el ingeniero Tomás Tauste, el agrimensor Pedro Casquer y Esteban Invernón, nivelador. Este equipo estaba bajo las órdenes del comisionado regio Juan de Tejada, del Consejo Real, que se había desplazado a Murcia por orden de Felipe II (firmada en Segovia el 15 de octubre de 1587) para que examinaran el proyecto presentado en el Consejo de Hacienda por la ciudad de Lorca para el trasvase de aguas de los afluentes del Guadalquivir, Castril y Guardal a los campos lorquianos y otras poblaciones del entorno de Cartagena. Al final este proyecto no llegó a ejecutarse. ${ }^{16}$

La villa de Almonte en el último tercio del siglo XVI. Las visitas de Bravo de Lagunas, Gilberto de Bedoya y Luis de Montalbán.

En aquellos ańos, la villa de Almonte, bajo la jurisdicción de la Casa de Medina Sidonia, pasaba por sus mejores momentos económicos, dada su posición geoestratégica cerca de Portugal, de Sevilla y de los puertos gaditanos. De sus 418 habitantes de $1534,{ }^{17}$ pasó a 2.774 (598 vecinos) en $1588,{ }^{18}$ producto de la inmigración más que del crecimiento vegetativo natural; población que se albergaba en unas 14 calles y su plaza pública, contando con 550 casas. La fisonomía urbana estaba plagada de casas-bodegas, con sus lagares de uva y aceite. El tráfico comercial hacia los puertos gaditanos era intenso y su ruta terrestre (Almonte-Moguer-El Rocío-Coto de Doña Ana) se encontraba plagada de mesones y ventas en dirección al sitio de Bonanza (Sanlúcar de Barrameda), ruta mucho más segura que la marítima por las acciones permanentes de las peligrosas flotillas turco-berberiscas e inglesas. La ganadería era la principal fuente de riqueza local, seguida del carbón, aceite, pesca y madera. Dos escribanías arrendadas por la Casa Ducal testimoniaban los negocios terrenales y espirituales. Una religiosidad popular pujante y en vertiginoso crecimiento daban fe de este desarrollo mantenido de su economía. A la altura del año 1580, existían en la villa de Almonte tres ermitas extramuros, la de Ntra. Sra. de Las Rocinas, la de Ntra. Sra. de la Hermosa y la del Señor Santiago, con su hospital; las casas y hospitales, con sus respectivas cofradías, de Ntra. Sra. de Gracia y de la Sangre de Jesucristo; el Hospital de Ntra. Sra. de La Asunción y las cofradías muy consolidadas del Santísimo Cristo de la Vera Cruz y del Santísimo Sacramento. En el año 1574 se fundó el convento de mínimos franciscanos paulinos de La

16 H. Capel, "Los proyectos del ingeniero militar Sebastián Feringan (1741) y de Francisco Boizot (1774) para el trasvase de los ríos Castril y Guardal con la construcción de un canal navegable y para el riego de los campos de Lorca, Totana, Cartagena y Murcia”. Biblio 3W. Revista Bibliográfica de Geografía y Ciencias Sociales, no 310 (2010), pp. 3-4.

17 A. Domínguez Ortiz, "La población del Reino de Sevilla en 1534", en Cuadernos de Historia, no VII (1977), pp. 345.

18 T. González, Censo de población de las Provincias y partidos de la Corona de Castilla en el siglo XVI, Imprenta Real, Madrid, 1829, p. 335. 
Victoria. A lo largo de la segunda mitad del siglo XVI se llegaron a constituir medio centenar de capellanías de misas perpetuas, instituidas en su mayoría por las clases medias y altas, tanto de personas del estamento eclesiástico como civil, de propietarios de tierras, de ganaderos, mercaderes y armadores, así de vecinos como de forasteros de la villa; algunas bien dotadas con bienes raíces, que se situaban en Almonte y lugares comarcanos, como en la propia ciudad de Sevilla, y que perduraron hasta su total desamortización en la primera mitad del siglo XIX. ${ }^{19}$

La oligarquía local era el reflejo exacto de la situación socioeconómica del municipio, compuesto por un grupo de hombres hacendados de primera y segunda "contía", con riquezas que superaban los 3.000 y 2.000 ducados respectivamente, grandes propietarios de bienes raíces, fortunas ganaderas, mercaderes y armadores, a los que se les sumaban otros pocos clérigos de aquellas mismas familias que fueron adquiriendo bienes rústicos y urbanos al calor de los estipendios procedentes de las mandas piadosas y capellanías colativas. Grupo social que no superaba la treintena y que se repartían todas las esferas del poder político y religioso locales. Estas familias procuraban extender su radio de acción a la ciudad de Sevilla, abriendo casas y estableciendo matrimonios, y en otros casos adquiriendo prebendas eclesiásticas en su Iglesia Mayor. Llevaban los apellidos Almonte, Montes de Oca, Pichardo, Río, Caballero, Bejarano, Pinto, Rioseco, Pavón, Abreu, Barrera, Cabrera, Martín e Infante, como grupo de mayores y medianos hacendados.

La llegada de Bravo de Lagunas a la villa de Almonte se produce en el mes de julio de 1577 , donde el día cinco convoca a su ayuntamiento en las casas donde residía, propiedad del vecino Hernando Caballero de León, en presencia del escribano público Juan de Gracia; ${ }^{20}$ allí les comunica el proyecto real de construir cuatro torres vigías en Arenas Gordas con la artillería, munición y guardas, a costa por mitad del concejo de la villa de Almonte y del duque de Medina Sidonia, concretamente las de "cruz de Salvar y la otra en Carvonero y otra en la Higuera y otra adelante entre la Higuera y el río del Oro"; con sus nombres hoy conocidos de Zalabar, Carboneros, Higuera y Asperillo. El gobierno de la villa de Almonte, como todos los pueblos afectados, y aquí al unísono, puso todos los reparos posibles a tan elevadas contribuciones. En primer lugar, alegaron que la villa estaba muy alejada de la costa, por lo que siempre ha "estado muy segura de moros y turcos"; en segundo lugar, que la villa no tiene puerto alguno en sus playas que hayan de ser guardados, ni tiene vecinos que se aprovechen

19 D. Muñoz Bort, "El Ayuntamiento de la villa de Almonte y la expansión de la devoción a la Virgen del Rocío (siglos XIV-XX). Parte segunda", Revista ExVoto, Año II, no 1 (2012), pp. 24-26.

20 Este acta municipal no se conserva en el tomo encuadernado correspondiente a este año en las A(ctas) C(apitulares) en el A(rchivo) M(unicipal) de A(lmonte). La hemos obtenido en MoraFigueroa, Torres de almenara ..., op. cit., pp. 98-100. 
de la pesca de dicha mar de Arenas Gordas, por lo que "nunca jamás se ha visto que moros y turcos cautivasen a los vecinos de esta villa"; también se aclara que las haciendas de pesquerías y los armadores que hay en sus playas son de vecinos de Sevilla, Cádiz, Puerto de Santa María, Huelva, Moguer, Palos y San Juan del Puerto que abastecen de pescado a Sevilla y a casi toda Andalucía, sobre quienes deberían recaer la construcción de dichas torres, y no sobre sus vecinos, que en número de cuatrocientos (1.858 habitantes) son todos muy pobres y miserables, viviendo sólo de su jornal. Ante esta situación, el cabildo propone que, además de los hacendados de pesquerías de sus playas, contribuyan a estos gastos los propietarios de los navíos naturales y extranjeros que mercadeaban con los anteriores, así como que el Rey permita al ayuntamiento la imposición de nuevas alcabalas y sisas y vender las yerbas de algunas dehesas y cepa para carbón de los baldíos del término.

En algunos de estos argumentos el concejo almonteño exponía menguada su realidad socioeconómica, además de seguir casi al dictado la posición que la Casa Ducal mantenía en este punto sobre la construcción de las pretendidas torres y fortalezas en sus estados, llegando incluso el propio Duque a defender la lejanía de la villa de Almonte y la "pobreza de sus gentes", dos meses antes que Bravo de Lagunas se reuniera con el concejo de la villa de Almonte. ${ }^{21}$ Sí era cierto que la villa de Almonte no tenía puertos en su extensa costa, también lo era que disponía ésta de varios poblados costeros dedicados a la pesca de bajura (xabegas) como los de La Higuera, Atarazanas o Asperillo y el del Río del Oro. Este último fue el más importante de todos a lo largo del Antiguo Régimen, ${ }^{22}$ con unos 250 a 400 hombres residiendo permanentemente todo el año. El Ayuntamiento concedía una media anual de 20 a 30 licencias para construir casas pajizas, ${ }^{23}$ bajo su tasa correspondiente, ${ }^{24}$ y cada ańo nombraba su delegado municipal que ejercía también a modo de alguacil con el título de "Fiel de la Renta de los Asientos del Río del Oro"25. Eran igualmente abundantes las licencias para hacer chozas al objeto de vender mercaderías a los asentados. ${ }^{26}$

21 Mora-Figueroa, Torres de almenara ..., op. cit., pp: 88 y 93 .

22 A.F.C.M.S., leg. 697. La antigüedad de este poblado costero se remonta a la Baja Edad Media, pues en 1481, un tal Juan García, espartero, tenía varias "casas", un "palacio" de madera, molino y vińas.

23 A.M.A., leg. 2. "Concediósele para que haga la dicha casa con que en el sitio no tome prescripción y si la vendiere no pueda vender el asiento de ella, sino la rama y madera que en ella hiciere, y de esta manera se le da licencia y que para la madera no se de licencia de alcornoque ni de madrońo, porque solamente se le de saos y sabina. Todo se de sin perjuicio de tercero". A. C. de 20 de febrero de 1587.

24 A.M.A., leg. 2. Esta consistía en el pago de 4 ducados al obtener la licencia y 3 reales anuales mientras que disfrutase de dicho asiento. A. C. de 25 de septiembre de 1593.

25 A.M.A., leg. 1. A. C. de 29 de diciembre de 1577. Y así cada final de año.

26 A.M.A., leg. 2. "En este cabildo pidio licencia Francisco García Ligero para hacer una choza 
La importancia poblacional y económica de este enclave pesquero fue de tal calibre que incluso se llegaron a fabricar dos molinos harineros por el hacendado y presbítero almonteńo Juan Pinto, en los peores años de los ataques corsarios turco-berberiscos en las playas de Arenas Gordas. ${ }^{27}$ Algunos de los armadores de estos poblados eran vecinos de Almonte, con casas abiertas, y propietarios de valiosos bienes rústicos y de ganaderías, como se desprende de las abundantes actas notariales que suscribieron Luis Martín, Juan Hernández, Manuel Rodríguez, Francisco Gutiérrez, los hermanos Juan y Antón Suárez y Bartolomé Martín en las dos escribanías existentes durante la segunda mitad del siglo XVI (años de 1562 a 1590).

En cuanto a los "cautivos de moros", el concejo almonteño eludía totalmente su responsabilidad, pues eran constantes en sus costas los apresamientos de sus vecinos armadores, pescadores y comerciantes en sus poblados costeros. Precisamente la costa de Arenas Gordas fue la zona de Andalucía con más presencia y visita de estos corsarios norteafricanos para sus aguadas y actos delictivos, como dejó constancia el comendador Bravo de Lagunas en su visita a estas costas en 1577:

... he estado visitando los sitios de Arenas Gordas, que no poco trabajo me han dado, por ser la tierra desierta y tan peligrosa de sí, tal que si no ando cargado de arcabuceros y hombres de caballo no lo podría hacer. Y delante de mis ojos vi tomar cuatro carabelas y estar sacando la ropa dellas, y sacada las dieron barrenos, y si como llegué tarde a la costa llegara una hora más temprano, me tomaran a mí y a los que iban conmigo, porque tenían cinco galeotas más adelante en una punta, y las dos que saqueaban las carabelas, de manera que me tomaban en medio, y a la parte de tierra hay unos barrancos que el tiempo los ha hecho una muralla muy alta y por otra parte la mar.$^{28}$.

en la playa, termino de esta villa al Río del Oro, para vender allí los mantenimientos necesarios y atento ser útil y provechoso se le concedió la dicha licencia, atento que es utilidad, lo cual se le concedió sin perjuicio de tercero". A. C. de 30 de diciembre de 1590.

27 A.M.A., leg. 3. "En este cauildo, Juan Pinto, presbítero, vezino de esta uilla, dió vna petición para que se le de lisensia que en el Chorrillo de el Río del Oro pueda hazer dos molinos. Acordóse que se le de lisencia para que pueda labrar los dichos molinos y que si fuere necesario darle título se le de hecha la dicha fábrica cada [vez] que le pida y sea necesario. Ansin lo acordaron y firmaron". A. C. de 21 de diciembre de 1613.

28 Sancho de Sopranis, "El viaje de Luis Bravo de Laguna ..., op. cit. El texto tomado de Villegas Martín et al.: "Nuevas aportaciones ..., op. cit., p. 117. 
En el verano de 1581, de mucha actividad del corso en nuestras costas, ${ }^{29}$ las Justicias de Almonte, por orden del duque de Medina Sidonia, se afanaban en buscar y detener a un grupo de moros en su costa de Río del Oro y otros parajes próximos, con lo que se demuestra una presencia incluso en tierra de estos norteafricanos:

En este cabildo se vido una carta de su excelencia en que manda que se vayan a buscar los moros que andan huidos y aunque se ha ido por dos partes a buscarlos y no se han hallado, se acordó que se vaya luego a buscarlos, y se junten los de a caballo y los mejores arcabuceros que se hallaren, para que se vayan a buscar.

Asimismo se acordó que para la ida de buscar los moros se tomen dos fanegas de trigo de las que el pósito cambió a ducado, y otras de cebada, y se compre vino, lo cual se pague del qoncejo porque irán pobres a ello, que no ternán [sic] que llevar de comer. ${ }^{30}$

En este cabildo se trató que se ha ido a buscar los moros por mandado del duque mi señor al Río del Oro y otras partes, y porque se quedó para ir a el Algayda de la Pez, donde podría ser que estuviesen, que respecto de no ir por el bosque no se fue allá, acordose que se vuelvan a ir a el Algayda de la Pez y que a ello salga el señor alguacil mayor, y lleve consigo los hombres que le pareciere, que sean arcabuceros y dos hombres de a caballo. ${ }^{31}$

La flota comercial española era igualmente atacada y saqueada, como fue el caso de una carabela de Sanlúcar de Barrameda en el verano de 1585, que "huyendo de moros" embarrancó entre las playas de La Barrosa y Carboneros. ${ }^{32}$ En un informe de Gilberto de Bedoya sobre su actuación en las torres de la costa de Andalucía, datado hacia junio de 1587 , se incide nuevamente en esta presencia continuada de corsarios norteafricanos en las costas de la villa de Almonte:

Están mandadas hazer otras tres torres en los sitios que diçen de Carbonero, La Higuera y el Orado, en la costa de Arenas Gordas,

29 En estos mismos días fue apresado en Arenas Gordas Juan de Vega Garrocho por el corsario Papasali, precisamente cuando regresaba de la jornada de Larache combatiendo a las órdenes del Duque de Medina Sidonia. En Gozálvez Escobar, "La piratería y la redención de cautivos ..., op. cit., p. 374.

30 A.M.A., leg. 1. A. C. de 1 de septiembre de 1581.

31 A.M.A., leg. 1. A. C. de 7 de septiembre de 1581.

32 A.P.N.L.P.C., leg. 5, fotogramas 241-242. Escritura de compromiso para reflotar una carabela propiedad de un vecino de Sanlúcar de Barrameda y varios vecinos de la villa de Almonte por importe de 47 ducados en reales. Almonte, 1585. Escribanía de Diego Dávila. 
tierra del duque de Medina Sidonia, que es lo más peligroso de toda la costa y a donde acuden los moros muy de hordinario y con la mesma livertad que en Bervería ... ${ }^{33}$

Una de las acciones de apresamientos de vecinos de Almonte más destacadas fueron los casos del armador Luis Martín, apresado en abril de 1565 con un nutrido grupo de sus trabajadores, vecino por el que se llegó a pedir 500 ducados de plata de rescate por parte del corsario que lo tenía retenido en la ciudad de Alcázar (actual Alcazarquivir de Marruecos) ${ }^{34}$; y, en mayo del mismo año, fueron hechos cautivos los vecinos Martín García y Hernando Alonso. ${ }^{35}$ Los continuos apresamientos y visitas de “moros" en estas costas llegaron a producir una verdadera alarma social en la población de Almonte, que se vio reflejada en la testamentaría de la época a partir del año 1586, donde a la manda obligatoria de ofrecer 5 maravedíes para las ermitas, santuarios y obras pías del Arzobispado de Sevilla, se sumaba ahora en el protocolo testamentario la de "redención de cautivos" ${ }^{36}$ Incluso algunos testadores incluyen una manda de ciertos dineros "para el primer cautivo de la villa Almonte" que se produzca tras su muerte. ${ }^{37}$

En cuanto al número de vecinos de la villa de Almonte, el concejo alega que sólo dispone de 400 vecinos, pero esta cifra no es exacta y creemos que dicho cómputo se ha disminuido intencionadamente, según manifiestan los padrones contemporáneos que elevan el total a 598 vecinos para el ańo 1588, o bien a 600, como informaba Bravo de Lagunas en $1577 .{ }^{38}$ Sobre la pobreza general del vecindario y que su mayoría fuesen asalariados, habría que matizar esta realidad ofrecida por los regidores almonteños. Su cabildo realmente no poseía bienes raíces de propios por estos años, sólo una casa recién adquirida para construir la casa capitular y audiencia propias, que no se inaugurarían hasta 1619. Sin

33 Villegas Martín et al.: "Nuevas aportaciones ..., op. cit., p. 122. La torre de "El Orado" que cita se corresponde con la actual de Asperillo. En documentos de finales del XVI aparece el topónimo "Asperillo del Orado", concretamente los que hablan de la construcción de una torre en este lugar. A.F.C.M.S., leg. 895.

34 A.P.N.L.P.C., leg. 1, fotograma 433. Poder de Inés Prieta, mujer de Luis Martín, cautivo de moros, a Gonzalo Díaz Hurtado, clérigo cura presbítero, para obtener de las Justicias licencia para poder vender algunos inmuebles y fincas rústicas para el rescate. Almonte, 1565. Escribanía de Alonso Méndez.

35 A.P.N.L.P.C., leg. 1, fotograma 435. Testamento de Cristóbal Martín Carruchena. Almonte, 1565. Escribanía de Alonso Méndez. En Mora-Figueroa, Torres de almenara ..., op. cit., p. 113, (Consejo de Guerra de julio de 1608) se informa que "en este ańo se han llevado de la costa de Arenas Gordas çinquenta personas".

36 A.P.N.L.P.C., leg. 6, fotograma 133.Testamento de Diego Martín Rosón. Almonte 1586. Escribanía de Diego Dávila.

37 A.P.N.L.P.C., leg. 15, fotograma 561.Testamento de Catalina García. Almonte, 1598. Escribanía de Sebastián de Cabrera.

38 Mora-Figueroa, Torres de almenara ..., op. cit., p. 96. 
embargo sus bienes comunales eran extensos para el pastoreo, la madera y la instalación de colmenas, y a través de arbitrios, tasas y ventas, permitían mantener una hacienda municipal con recursos importantes. Como comentábamos arriba, sólo un reducido grupo de una treintena de familias superaban el millar de ducados en rentas, y el resto de vecinos eran asalariados o pequeños propietarios de bienes raíces, cuyos porcentajes exactos desconocemos por el momento para el último tercio del XVI. ${ }^{39}$ Las transacciones comerciales analizadas en las escribanías públicas de Almonte entre los años 1562 a 1590 crecen anualmente a buen ritmo, así como los vecinos que se declaran mercaderes de un variado consumo (carbón, paños, árboles frutales, animales de labranza y tiro).

Pero a pesar de estas quejas e imposibilidades económicas del pueblo declaradas por el concejo, su gobierno municipal no se unió al resto de pueblos que litigaron contra la Corona por desacuerdo en el repartimiento para la construcción de estas torres vigías, como fueron los casos mancomunados de Moguer, Palos, San Juan del Puerto, Huelva, Gibraleón y Cartaya, o de Ayamonte individualmente. ${ }^{40}$

El día 24 de noviembre de 1585, Gilberto de Bedoya notifica al concejo de Almonte la provisión real que le nombró Juez de Comisión para la construcción de las torres vigías de las costas de Andalucía, acordándose por sus regidores que se consultara con un letrado aquel mandamiento y que se diese cuenta de este asunto al duque de Medina Sidonia. ${ }^{41}$ El 19 de abril de 1586 Bedoya exige al concejo de Almonte su parte alícuota en la contribución para las torres de su término, cifrada en 500 ducados (187.000 maravedíes), aduciendo que " $h a$ menester para pagar la gente que anda sacando material en el río del Oro para la fábrica de las dichas torres", ${ }^{42}$ dándole un plazo de tres días. Dicha orden tuvo eficacia y al día siguiente se acuerda por el concejo almonteño sacar a subasta 30.000 costales de cepa de brezo de sus montes comunales para acudir a tal demanda del juez; opción que evitaba una imposición directa o repartimiento general sobre su vecindario. ${ }^{43}$

Estos 187.000 maravedíes que correspondieron a la villa de Almonte para la torre del Río del Oro sólo fue superado por las de Lepe (582.980), Cartaya (239.750) y Ayamonte (206.960), a pesar de que en el territorio almonteño se planearon construir otras cinco torres. Estos datos parecen apoyar que la Casa de Medina Sidonia iba a correr con la casi totalidad del presupuesto destinado

39 Cálculo ponderado efectuado a través de los documentos: "Año 1549. Vecindario del Estado de Medina Sidonia". A.F.C.M.S., leg. 959; y "Vecindario y caudales de los pueblos del Estado de Medina Sidonia. Año 1778”, A.F.C.M.S., leg. 694.

40 Villegas Martín et al.: "Nuevas aportaciones ..., op. cit., p. 104.

41 A.M.A., leg. 2. A. C. de la fecha.

42 A.M.A., leg. 2. A. C. de la fecha.

43 De similar forma se ejecutó por parte del concejo de Cartaya. En Ayamonte se recurrió a un empréstito con particulares. Villegas Martín et al.: "Nuevas aportaciones ..., op. cit., pp. 103-104. 


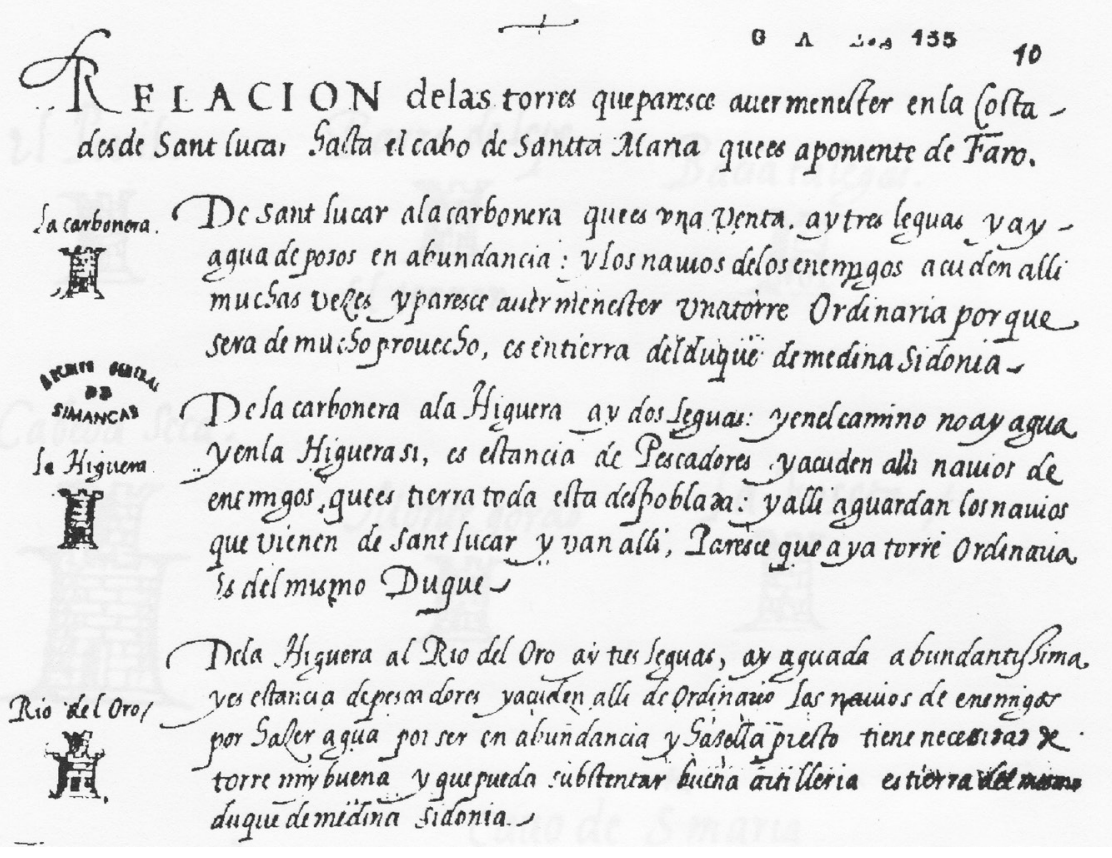

Relación de las torres que paresce auer menester en la Costa desde Sant Lucas hasta el cabo de Santa María que es a poniente de Faro. Extracto. A.G.S., G. A., S/F (a. 1583), leg. 155/10. Tomado de A. CÁMARA MUÑOZ, (1990:64).

al litoral del término de Almonte, al adjudicarle el Licenciado Bedoya casi dos millones de maravedíes (1.986.200). ${ }^{44}$ Pero como veremos más adelante, el coste total para Casa Ducal fue bastante más elevado.

No hemos encontrado ningún recibo ni escritura de tal abono, pero otros documentos confirman de que el pago se efectuó, ya que años más tarde el ayuntamiento de Almonte intenta recuperar este dinero nombrando procurador en Madrid. ${ }^{45}$ ¿'Se debe esta acción a que los otros pueblos ganaron el pleito interpuesto? Más bien parece que esta presión local obligó a la Corona a sentenciar en 1590 que del cordón de torres, trece serían financiadas por los señores jurisdiccionales. ${ }^{46}$ Otro

44 Ibídem, op. cit., p. 102.

45 A.M.A., leg. 2. A. C. de 3 de marzo de 1591. Hay otros acuerdos en este sentido de los ańos 1592, 1595 y 1596. En este último de 12 de enero se le comunica al procurador de Madrid, Lope de Vergara, que si es necesario para agilizar las diligencias del cobro de los 500 ducados, se le ofrezcan al propio Gilberto de Bedoya 50 ducados, ya que en aquellos días era Relator de uno de los consejos reales.

46 A(rchivo) H(istórico) N(acional), Nobleza, Osuna, leg. 382, 41-43, citado por A. Mira Toscano y J. Villegas Martín, "La torre de Sierra Bermeja o del Catalán”, en A. Díaz Zamorano y J. 
acuerdo de los munícipes almonteńos de 1592 para recuperar aquel dinero, parece confirmar esta hipótesis:

... y más se acordó que porque a este qoncejo les llevó y tomó el licenciado Gilberto de Bedoya, juez que fue de la mensatura [sic] de la torre de la costa del Andaluzía diciéndoles cabrá a esta dicha villa y porque cierto no se les debía repartir ni traía tal orden no se hicieron la dicha torre en término de esta villa que sirviéndose Su Magestad de mandar que se cobren los dichos quinientos ducados del dicho Gilberto de Bedoya o de la persona que los dejó depositados. ${ }^{47}$

Desconocemos el momento exacto de la llegada de Luis de Montalbán a la villa de Almonte. Los primeros documentos lo sitúan como vecino en los primeros meses de 1586, sin dejar su residencia sevillana en la collación de la Magdalena. ${ }^{48} \mathrm{Y}$ su reputación de ingeniero hidráulico era conocida por el gobierno local, que en octubre de ese mismo año le encarga las obras necesarias para aumentar el caudal del Pozo del Pilar, principal abastecedor de agua potable de la villa. ${ }^{49}$ Otros documentos de ese año lo señalaban ya como mercader de carbón en la propia villa, siendo uno de los principales compradores de la cepa de los montes de propios y comunales. ${ }^{50}$

Las paralizaciones de las torres vigías en la costa almonteña y en el resto de la onubense actual, además de los impagos de algunas adjudicadas mediante contratación a Luis de Montalbán, propició que nuestro ingeniero se dedicase en la villa de Almonte a vivir de algunos de los negocios o mercaderías más pujantes de la época, como el carbón y las pieles, productos abundantes en esta zona ganadera y de monte bajo muy extenso, sin olvidar que seguía ligado por estos años a la ciudad de Sevilla en el mantenimiento de las fuentes públicas. En el caso del carbón, Luis de Montalbán actúa en compañía de Diego Martín de Rioseco, hacendado de Almonte. Precisamente la primera compra de cepa de brezo de esta compañía al gobierno de este lugar se produce cuando éste necesita dineros para cumplir la requisitoria del juez comisionado real para la

Otero Prieto (Ed.): El lugar heredado. Huelva, 2009, p. 26. En el A.F.C.M.S., leg. 894, se conserva una Real Provisión de 1590 sobre este mismo asunto.

47 A.M.A., leg. 2. A. C. de 6 de mayo de 1592.

48 A.P.N.L.P.C., leg. 8, fotograma 285. Escritura de compromiso de Rodrigo Martín, vecino de Rociana, de sacar toda la cepa que Luis de Montalbán, "vecino de Sevilla en la colación de la Madalena", tiene comprada al gobierno de la villa de Almonte. Almonte, 1590. Escribanía de Diego Dávila.

49 A.M.A., leg. 2. A. C. de 8 de julio y de 22 de julio de 1586.

50 A.M.A., leg. 2. A. C. de 11 de julio de 1586. 
construcción de las torres vigía, Gilberto de Bedoya, que le exigió 500 ducados como acabamos de ver. Sacada a subasta pública, se adjudica el primero de mayo de 1586 a la compañía Montalbán y Rioseco la venta de 30.000 costales por importe de 464.000 maravedíes, es decir 1.243 ducados, con un plazo de tres años para su extracción total. ${ }^{51}$ Luego se buscaban los hombres necesarios para la entresaca y la propia fabricación de este carbón tanto de Almonte como de otros de la comarca, por precio que oscilaba entre 22 y 28 reales la carretada de carbón. ${ }^{52}$ Otra de sus actividades empresariales fue la compraventa de corambre o pellejos de animales sacrificados en las carnicerías de Almonte y de los pueblos comarcanos. ${ }^{53}$ En Almonte existían varias fábricas de pieles o curtidurías instaladas en la calle de su nombre, en el perímetro noreste del casco urbano.

Luis de Montalbán poseía algunos bienes raíces en el término de Almonte, concretamente dos viñedos en el sitio de la Cańada de 2.000 y 1.000 cepas respectivamente, y otra viña de 2.000 cepas en el pago de El Chaparral. ${ }^{54}$ También poseía un esclavo negro y una esclava morisca que le regaló o compró en Jerez a su hermano Francisco de Montalbán. ${ }^{55}$

Las sucesivas ventas de sus bienes en Almonte a lo largo de 1589, su ausencia de la villa y la paralización de las obras de las torres vigías, alertan a sus fiadores y proveedores. El presbítero hacendado Pedro de Montesdoca llegó a cobrarse alguna deuda de Luis de Montalbán, presentándose en su casa de Sevilla y llevándose por la fuerza algunos objetos de plata en presencia de su mujer. ${ }^{56}$ En el año 1590 el ayuntamiento de Almonte pone pleito a Luis de Montalbán para que pague sus deudas pendientes de la saca de cepa de brezo; incluso su síndico

51 A.P.N.L.P.C., leg. 6, fotograma 233. La escritura se otorga el 6 de mayo de 1586 en la Escribanía de Diego Dávila.

52 A.P.N.L.P.C., leg. 6. La carretada contenía 20 costales de la "medida de Hinojos". Este carbón de brezo era muy demandado para la fragua de los herreros. Los fotogramas 500 a 541 de la Escribanía de Diego Dávila del año 1586 son de contratos de terceros para hacer carbón.

53 A.P.N.L.P.C., leg. 7, fotograma 459. Concierto entre Luis de Montalbán y Fernando Martín Espina, vecino de Rociana, por el cual éste último ha de entregar al primero toda la corambre de la carnicería del lugar de Rociana que se produjere entre los meses de septiembre de 1588 a carnestolendas de 1599. Almonte, 1589. Escribanía de Diego Dávila.

54 A.P.N.L.P.C., leg. 7, fotogramas 91, 95 y 175. Almonte, 1589. Escribanía de Diego Dávila.

55 Romero Bejarano, "El gran engaño del agua ..., op. cit., p. 1215. Son los mismos esclavos, ella ahora parida de una hija, que le vende a Diego Martín de Rioseco en 1589 por precio de 250 ducados. A.P.N.L.P.C., leg. 7, fotograma 480. Almonte, 1589. Escribanía de Diego Dávila.

56 A.P.N.L.P.C., leg. 7, fotograma 7. Poder general otorgado por Luis de Montalbán a Gaspar Gutiérrez, boticario, y a Diego Brasa, vecinos de Sevilla, para que se querellen contra el Lcdo. Pedro de Montesdoca, clérigo y cura de Almonte "en razón de haber el susodicho llevádome un caldelero y dos cubiletes y otras cosas de plata de las casas de mi morada diciendo a Dońa María, mi mujer, era para pagar cierta deuda y para ello ganar cualesquier cartas y censuras así por la dicha vía criminal”. Almonte, 1589. Escribanía de Diego Dávila. 
procurador solicita el 13 de abril al concejo de la villa que se le mande prender, solicitud que se aprueba por el alcalde mayor. ${ }^{57}$ La venta de sus bienes en la villa y el rumor de que se retiraba a Madrid, alarmaron a las autoridades almonteñas, quienes decretaron el embargo preventivo de sus bienes y le citaron en la villa. A lo largo de los meses siguientes, Luis de Montalbán acude periódicamente a Almonte y negocia con sus deudores y fiadores, resolviendo las demandas de unos y otros mediante pagos, compromisos y fianzas a través de una serie de escrituras públicas.

Ante el requerimiento del ayuntamiento de Almonte del mes de mayo de $1590,{ }^{58}$ Luis de Montalbán, por escritura pública de junio, se compromete a liberar la fianza dada por Diego Martín de Rioseco para la venta de los 30.000 costales de cepa, ajusta con el ayuntamiento que le tiene pagado 231.336 maravedíes y que resta por pagar 233.164, para lo cual entrega el día de la firma 100 ducados, y hace compromiso de pagar el resto en tres pagas consecutivas cada seis meses; y el ayuntamiento le da un nuevo plazo de 20 meses para acabar de sacar la cepa que le resta. ${ }^{59} \mathrm{~A}$ continuación liquida las cuentas de carbón con su socio Diego Martín de Rioseco. ${ }^{60}$

El último asunto que tendría que resolver Luis de Montalbán antes de su partida definitiva de Almonte, fue el de anular las fianzas que varios vecinos de Almonte y Sevilla le prestaron para la ejecución de las torres vigías de los términos de Almonte, Palos y Lepe. Mediante escritura pública de 7 de agosto de $1590,{ }^{61}$ Luis de Montalbán libera las fianzas dadas por los vecinos de Almonte Diego Martín de Rioseco, Juan Martín Abad, Hernando Pinto y Acacio Alonso y del vecino de Sevilla Jerónimo de Melgarejo, ofreciendo para ello una fianza abonada de 6.000 ducados, un salario diario de 300 maravedíes para la persona que tenga que hacer alguna gestión para localizarle y una multa además de 100.000 maravedíes si no cumpliese este compromiso. En la escritura se contiene además la subrogación de Diego Martín de Rioseco para acabar las obras de dichas torres, cediéndole también Luis de Montalbán una sentencia por la cual la Corona reconoce una serie de deudas pendientes por las obras ejecutadas por

57 A.M.A., leg. 2. A. C. de 13 de abril de 1590.

58 A.P.N.L.P.C., leg. 8, fotograma 203. Poder general para pleitos a un procurador de Sevilla. Almonte, 1590. Escribanía de Diego Dávila.

59 A.P.N.L.P.C., leg. 8, fotograma 233. Carta de reconocimiento de deuda y pagos del Gobierno de Almonte a Luis de Montalbán, vecino de Sevilla, y a Diego Martín de Rioseco, su fiador y vecino de Almonte, por la licencia para sacar de los montes del término 30.000 costales de carbón. Almonte, 1590. Escribanía de Diego Dávila. Esta concordia se había acordado por el gobierno de Almonte en su reunión capitular de 15 de junio de 1590. A.M.A., leg. 7.

60 A.P.N.L.P.C., leg. 8, fotograma 436. Escritura de concierto entre Luis de Montalbán y Diego Martín de Rioseco, por la cual Luis de Montalbán pagará al gobierno de Almonte 74.554 maravedíes y a Diego Martín 1.800 reales. Almonte, 1590. Escribanía de Diego Dávila.

61 A.P.N.L.P.C., leg. 8, fotograma 297. Almonte, 1590. Escribanía de Diego Dávila. 
Luis de Montalbán hasta el momento en dichas torres; es decir, Rioseco acabará las obras recibiendo los pagos previstos para ello, y las deudas contraídas por la Corona con Luis de Montalbán por las edificaciones ejecutadas hasta la fecha. Diego Martín de Rioseco tampoco las finalizaría, pues por 1598 se hallaba en América. ${ }^{62}$

4. La aportación de Luis de Montalbán a la construcción de las TORRES VIGÍAS ONUBENSES.

El sistema defensivo y de vigilancia de la costa de Andalucía, con un total de 45 torres desde Ayamonte a Gibraltar (de las cuales 19 estaban levantadas), fue ideado, tras el reconocimiento efectuado por el Capitán General de Artillería Francés de Álava y Vespasiano Gonzaga en 1575, por orden expresa de Felipe II. Al año siguiente se ordenó la partida del comendador Luis Bravo de Lagunas con el ingeniero Antonelli para la construcción de las nuevas; ${ }^{63}$ sin embargo, en el Consejo de Guerra celebrado el 31 de julio de 1608 se dice que a Bravo de Lagunas le acompañó el ingeniero Juan Pedro Livadote, para el diseño de las torres. ${ }^{64}$ Pero no es hasta primero del mes de marzo de 1577 cuando llega a la costa gaditana Bravo de Lagunas y aquí espera la llegada del maestro mayor de obras del Reino de Granada, Juan Antonio Malgrá, encargado del diseńo de tales torres. ${ }^{65}$

Bravo de Lagunas inicia sus actividades en Gibraltar, Tarifa y Puerto Real durante los meses de marzo y abril, y estaba acompańado por Malgrá y Juan Pedro Livadote, ${ }^{66}$ pero también por Luis de Montalbán, que personalmente llevó a la Corte la relación de las torres que se habían de efectuar desde Sanlúcar hasta Ayamonte, según se desprende de la carta enviada por Bravo de Lagunas al Rey desde Puerto Real, fechada en 4 de abril de 1577; y por otra misiva con el mismo destino, también en Puerto Real en 10 de abril, Luis de Montalbán fue el que estudió los aspectos técnicos y prácticos de las trazas de las torres de Sanlúcar, Arenas Gordas y Río del Oro. ${ }^{67}$

Esta presencia de Luis Montalbán en los trabajos preliminares de la ubicación y diseño de las torres desde Sanlúcar hasta Ayamonte sin designación real ni

62 A.P.N.L.P.C., leg. 15, fotogramas 535-536. Poder general para pleitos otorgado por Inés de la Barrera, mujer legítima de Diego Martín de Rioseco, ausente en Indias. Almonte, 1598. Escribanía de Diego Dávila.

63 Cámara Muñoz, "Las torres del litoral ..., op. cit., p. 62.

64 A.G.S., G.A., leg. 698, en Mora-Figueroa, Torres de almenara ..., op. cit., p. 112.

65 Cámara Muñoz, "Las torres del litoral ..., op. cit., pp. 62-63.

66 Consejo de Guerra de 31 de julio de 1608. También en Cámara Muñoz, op. cit., p. 68. Para esta autora, fue Juan Pedro quien hizo las trazas y mediciones de las torres que serían situadas desde Gibraltar hasta Ayamonte cuando su viaje con Bravo de Lagunas.

67 A.G.S., G.A., leg. 83/45, en Mora-Figueroa, Torres de almenara, op. cit., pp. 88-89. 
del Consejo de Guerra -no la hemos hallado- es una cuestión que nos llama la atención, salvo que de forma voluntaria ayudara en estos trabajos por recomendación del Conde de Barajas, con el que hacía años trabajaba en el abastecimiento de aguas a Sevilla, o la de su hermano Francisco Montalbán, ingeniero real y de plena confianza de Felipe II, esperanzado quizás de que en algún momento se le contratase para la ejecución directa de las futuras obras de construcción de aquellas torres. El mismo Bravo de Lagunas recomienda al Rey la dirección de las obras de Arenas Gordas por Luis de Montalbán, que "es un hombre platico y maestro de cantería y está aqui mas a la mano, y el conde de Barajas quando passé por Sevilla me dijo la mucha avilidad que tenía en lo que toca a esto de torres y otras cosas semejantes". ${ }^{68} \mathrm{~A}$ estas recomendaciones se unió también la de Francés de Álava, que en 1581 proponía que las trazas que diera el ingeniero de estas torres las ejecutaran "un Montalván que reside en Sevilla y un Juan Cornejo en Gibraltar", ${ }^{69}$ por lo que la profesora Cámara deduce que Luis de Montalbán quedó como encargado de la construcción de las torres, posiblemente hasta la llegada de su hermano Francisco en diciembre de 1586. Sobre este particular tenemos dudas razonables; en primer lugar por la total paralización del proyecto tras la marcha de Bravo de Lagunas, y también porque veremos posteriormente a Luis de Montalbán ejerciendo de contratista de estas obras, antes incluso de la llegada de su hermano.

Bravo de Lagunas abandona Andalucía desde Sevilla tras dejar sentado con el Alcalde de la Mar de la ciudad, en 22 de agosto de 1577, el transporte de las piedras de Chiclana a Arenas Gordas por parte de los barcos que abastecían de pescado a esta ciudad. El proyecto quedó paralizado desde aquel año hasta que Gilberto de Bedoya vuelve a nuestras tierras en noviembre de 1585 con la intención de reanudar, o más bien comenzar, la construcción de las torres con orden expresa de ejecutar una sentencia real, apelada por alguno, que obligaba a los señores jurisdiccionales a asumir los gastos de tales trabajos, ${ }^{70}$ coincidiendo con la dirección de las obras por parte de Francisco de Montalbán, que estaba nombrado por el Consejo de Guerra con salario de dos ducados diarios, cuando ejercía entonces de "maestro mayor de los edificios de agua del rey", como tuvimos ocasión de señalar, hasta mayo de 1588 , que por enfermedad desiste y es sustituido por Juan Pedro Livadote.$^{71}$

Vemos, pues, a un Luis de Montalbán que conocía bien el proyecto de construcción de estas torres y a los jueces e ingenieros encargados de dirigir y ejecutar tal proyecto, encontrándose en una situación privilegiada para

68 Ibídem, p. 89.

69 Cámara Muñoz, "Las torres del litoral ..., op. cit., p. 68.

70 Consejo de Guerra de 31 de julio de 1608, op. cit.

71 Cámara Muñoz, "Las torres del litoral ..., op. cit., p. 68. 
aprovecharse económicamente del mismo. Efectivamente, en 1586 y con la presencia en estas tierras del nuevo juez comisionado Gilberto de Bedoya y de su hermano Francisco como director de las obras, se hace con una de las contratas de las torres que debían situarse en el término de Lepe. Por escritura de traspaso firmado en la villa de Lepe en 13 de de septiembre, el vecino y albañil de esta villa, Diego Alonso, cede a Luis de Montalbán "la obra y fábrica de dos torres... que se dicen El Terrón y Sierra Bermeja", con la obligación de otorgar una fianza de 4.000 ducados:

Sepan cuantos esta carta vieren como nos don Guillermo de Melgarejo, vecino de la ciudad de Sevilla, morador en esta villa de Almonte, y Diego Martín de Rioseco, vecino que soy de esta dicha villa $[\ldots]$ otorgamos y conocemos que nos constituimos y salimos por fiadores y principales pagadores del dicho Luis de Montalván en la dicha cantidad de cuatro mil ducados y nos obligamos que el dicho Luis de Montalván hará las dichas torres y las fabricará y acabará, según y de la manera y condiciones, penas y posturas y obligaciones con que vos el dicho Diego Alonso estábais obligado, y si por no las hacer y cumplir con lo susodicho algún daño costas os hace os lo daremos y pagaremos como tales fiadores en la dicha cantidad de cuatro mil ducados por nuestras personas y bienes raíces y muebles habidos y por haber que para ello obligamos y damos poder cumplido a los jueces y justicias de los reinos y señoríos de Su Majestad, en especial al ilustrísimo señor el licenciado Gilberto de Bedoya, Juez de Comisión por Su Majestad para la fábrica de las torres. ${ }^{72}$

El documento en sí, aparte de apuntarnos una de las facetas de nuestro biografiado Luis, también nos indica otros pormenores desconocidos de las actuaciones del comisionado Gilberto de Bedoya para relanzar, tras casi una década paralizado, el proyecto de las torres vigías y defensivas de la costa de Andalucía. Resalta la rapidez de su actuación no sólo en efectuar los repartimientos y cobro de los dineros asignados a los seńores, municipios y armadores, sino también en la propia construcción de las fábricas. Y en el método empleado para la construcción de las torres, tanto de las torres pequeñas como de las grandes, por el procedimiento de la licitación pública con sus pliegos de condiciones

72 A.P.N.L.P.C., legajo 6, Fotogramas 398-399. Escritura de Fianza otorgada por Guillermo Melgarejo y Diego Martín de Rioseco a favor de Luis de Montalbán para el concierto y traspaso con Diego Alonso para la construcción de dos torres en la villa de Lepe. Almonte, 9 de octubre de 1586. Escribanía de Diego Dávila. 
económicas, técnicas y temporales, adjudicándose a contratistas con ciertos conocimientos constructivos como los maestros albañiles; construcción mediante el modelo conocido en la época como "destajo", en vez de por administración; método que siempre había defendido el ingeniero Livadote, mediante el cual se reducían los costes finales. ${ }^{73}$ No hemos visto la escritura de traspaso que se firmó en la villa de Lepe entre Luis de Montalbán y Diego Alonso fechada en 13 de septiembre de aquel ańo de 1586, pero seguro que contendría el pliego de condiciones correspondiente, el mismo que aceptaría con anterioridad el maestro Diego Alonso tras adjudicársele el remate de estas dos torres. En este documento aparecen dos de las torres que Luis Bravo de Lagunas ordena a los concejos de Ayamonte y Lepe construir: El Terrón y Sierra Bermeja ${ }^{74}$ situada esta última entre la de la Canela y la del Terrón. Suponemos que la primera "fuerte" y la segunda ordinaria o pequeña, según los textos citados. Cuando Bedoya rindió cuentas de los quehaceres de su comisión apuntó que la torre del Terrón no se comenzó; que la de Sierra Bermeja estaba levantada 20 pies sobre una cimentación de "quatro varas y ochava". También Gilberto de Bedoya deja constancia de que las torres de Sierra Bermeja, Marijata y Portechón las tenía a "destajo Luis de Montalvo", en clara referencia a Luis de Montalbán. ${ }^{75}$

En el otońo de 1588, con la presencia en estas tierras del nuevo director de las fábricas de la torres Juan Pedro Livadote, ${ }^{76}$ Luis de Montalbán obtiene en la villa de Huelva un nuevo remate para la construcción de 6 torres en Arenas Gordas, Arenilla y Cabeza Seca, y en 12 de diciembre del mismo ańo otorga la correspondiente fianza en la villa de Almonte. ${ }^{77}$

Según este nuevo documento, se habla de la construcción de 6 torres: una en Arenilla, término de Palos, otra en Cabeza Seca, término de Ayamonte y cuatro en Arenas Gordas. En este último extenso paraje sabemos que ya en tiempos de Gilberto de Bedoya se adjudicaron por remate las torres de Modolón y de Cruz de Zalabar a Juan Cordero, maestro mayor de obras de duque de Medina

73 Cámara Muñoz, "Las torres del litoral ..., op. cit., p. 69.

74 A.G.S., G. A., leg. 83. En Mora-Figueroa, Torres de almenara ..., op. cit., pp. 106-108.

75 Biblioteca Francisco de Zabálburu, Colección Altamira, caja 159, D-115: Relación del estado en que el licençiado Jilbert de Vedoya dexó de las torres de la costa de Andalucía y de los que se ha gastado en ellas. En Villegas Martín et al.: "Nuevas aportaciones ..., op. cit., pp. 121-123. Este documento es una de las inéditas aportaciones de estos investigadores a la historia de las torres almenaras andaluzas.

76 Llega a Gibraltar el 8 de octubre de 1588. En Cámara Muñoz, "Las torres del litoral ..., op. cit., p. 69.

77 A.P.N.L.P.C., leg. 7, fotogramas 273-278. Escritura de Obligación de varios vecinos de la villa de Almonte a favor de Luis de Montalbán, vecino de Almonte, y rematista de la construcción de seis torres en Arenas Gordas, Arenilla y Cabeza Seca en las costas de Andalucía. Almonte, 1588. Escribanía de Diego Dávila. Texto completo en Apéndice Documental. 
Sidonia. ${ }^{78}$ Con estos datos deducimos que aquellas cuatro torres en Arenas Gordas deberían ser las de Carbonera, Higuera, Asperillo y Río del Oro. Esta hipótesis quedaría aclarada definitivamente viéndose la escritura de remate que pasó ante el escribano público de Huelva, Andrés Martín. En la relación de los trabajos efectuados por Bedoya a principios de junio de 1587 no aparece la torre de Cabeza Seca, que iría ubicada en la isla Canela en la desembocadura del Guadiana. Esta carta de fianza sí que trae inserto el pliego de condiciones técnicas y económicas, extenso con 31 condiciones, y es lo más novedoso del documento, ya que afecta a seis torres, pues con anterioridad sólo conocíamos los pliegos de construcción de las torres de Modolón (San Jacinto), isla de Saltés y la de Punta Umbría, todos diseñados por Juan Ambrosio Malgrá en los tiempos de la visita de Bravo de Lagunas. ${ }^{79}$

Siguiendo las condiciones técnicas o trazas de estas torres, no podemos identificar a su autor; no descartamos a Ambrosio Malgrá ${ }^{80}$ con cuyas trazas reconoció en varias ocasiones Bravo de Lagunas los distintos emplazamientos de Arenas Gordas, ${ }^{81}$ pero tampoco los diseños propuestos por Juan Marín tanto para las torres pequeñas como las grandes; las primeras de una sola bóveda, con su terraplén macizo de un tercio de alto del total de la torre que tendría 60 pies (16,70 metros) y de ancho 23 pies (6,40 metros) y las segundas, de dos bóvedas, la misma altura total y del terraplén, 35 pies de ancho $(9,74$ metros) y con aljibe. ${ }^{82}$ Nuestro pliego da unas trazas principales de una altura total de 60 pies, el terraplén macizo tiene una altura que equivale al tercio del total, es decir, 20 pies y que dispondrá la torre de dos bóvedas, la primera de 11 pies de altura. Tendrá asimismo una escalera de caracol de piedra y su puerta al nivel superior del terraplén por la parte de tierra, de 69,5 de ancho por 111 centímetros de alto, reforzada con "hoza" de hierro y con barra de hierro para colocar la escala de soga y tranca de madera para su cierre desde el interior. Arriba su antepecho y ladrón vertical a la puerta para su defensa. Las obras se han de acabar en 18 meses sin interrupción y contará con la supervisión y visto bueno final de Juan Pedro Livadote "a cuyo cargo están la dicha fabrica de las torres del Andalucía por el Rey nuestro señor". Entre las condiciones económicas se especifica que dadas las fianzas oportunas, se le entregará al rematista 2.000 ducados y otros

78 Villegas Martín et al.: "Nuevas aportaciones ..., op. cit., pp. 122-123.

79 Mora-Figueroa, Torres de almenara ..., op. cit., pp. 90, 103-105 y 105-106.

80 El mismo reconoció su autoría de dichas plantas. En Mira Toscano et al., La torre de Sierra Bermeja ..., op. cit., p. 22. Estos autores se basan en la obra de Sancho De Sopranis: "El viaje de Luis Bravo de Lagunas ..., op. cit., pero no citan ni la procedencia del texto ni la página de dicha obra.

81 Mora-Figueroa, Torres de almenara ..., op. cit., p. 95 y Cámara Muñoz, "Las torres del litoral ..., op. cit., p. 71.

82 Mora-Figueroa, Torres de almenara, op. cit., pp. 44-48. 
tantos cuando finalice la cimentación y la fábrica alcance una vara de alto, y así sucesivamente recibirá dineros hasta su finalización. No disponemos sin embargo del precio final dispuesto en el remate; para ello habría que buscar la escritura de contratación que se efectuó en la villa de Huelva; pero de seguir los precios calculados por Juan Marín, aquel maestro "de la Puente y Fortificación de Cádiz", para estas torres grandes que calculó en 1.500 ducados, ${ }^{83}$ las seis torres podrían alcanzar un precio total en torno a 9.000 ducados, unos 3.366 .000 maravedíes. Pero si tenemos en cuenta la fianza impuesta para la construcción de las torres del Terrón y Sierra Bermeja de 2.000 ducados por cada torre, entonces hablaríamos de un monto total de 12.000 ducados. Pero, según el duque de Medina Sidonia, fueron otros los costes y mucho más elevados; por el año 1598 las torres de Carbonero y La Higuera, aún inacabadas, habían consumido 14.000 ducados; la del Río de Oro, acabada y de 60 pies de altura, costó 18.000 ducados; la de Arenilla, acabada y de 40 pies de altura, 10.000 ducados; y la de Sierra Bermeja, acabada y de 60 pies de altura, 6.000 ducados. ${ }^{84}$ En esta última, el ahorro podría estar en la parte construida por Luis de Montalbán, como veremos a continuación.

Pero a tenor de las obras finales ejecutadas, resulta que no todas estas seis torres se ejecutaron como tales torres grandes de que nos habla este pliego de condiciones, sino como torres grandes se ejecutaron las del Río del Oro y Cabeza Seca (Isla Canela), ordinarias pero algo más fuertes o gruesas las de Arenilla y Sierra Bermeja (El Catalán), que nos recuerdan a la de Modolón (San Jacinto), con una sola bóveda; y con trazas de ordinarias o simples las de Carbonera, Higuera, Horado (Asperillo) y El Terrón. ¿¿A qué se debieron estos cambios de diseño? ¿Falta de financiación, nuevas trazas de los directores en funciones Juan Pedro Livadote y Fernando Álvarez de Bohórquez, o nuevas instrucciones del Consejo de Guerra?

Luis de Montalbán inició la fábrica de algunas de las ocho torres que se le adjudicaron, pero no llegó a finalizar ninguna, pues por el año 1590, como avanzamos, cedió a terceros aquellas obras de sus dos remates e incluso los dineros que la Corona le debía por los trabajos efectuados en las torres de El Terrón y Sierra Bermeja. Así aparece reflejado en una escritura de liberación de fianzas otorgada por Luis de Montalbán en la villa de Almonte ante el escribano público Diego Dávila en el mes de agosto. ${ }^{85} \mathrm{Al}$ parecer Luis de Montalbán no había llegado a cobrar de la Corona los dineros recogidos en el remate de las

83 Ibídem, p. 44.

84 A.H.N., Nobleza, Osuna, leg. 382, 41-43. Citado por Mira Toscano et al., La torre de Sierra Bermeja ..., op. cit., p. 28.

85 A.P.N.L.P.C., leg. 8, fotogramas 297-299. Escritura de rescisión de fianzas otorgada por Luis de Montalbán a favor de varios vecinos de la villa de Almonte. Almonte. 1590. Escribanía de Diego Dávila. 
torres de El Terrón y Sierra Bermeja y cuyas obras tenía avanzadas, por lo que paró dichas obras y demandó a la Corona, obteniendo auto en su favor "ganado en el Gobierno del Rey nuestro señor en vista y revista en que por el se manda pagar todo lo que yo tengo labrado hecho y edificado en las torres que tuve a mi cargo en el término de la villa de Lepe que se dicen El Terrón y Sierra Bermeja". No cita en ningún momento las obras de Portechón y Marijata, que junto con la de Sierra Bermeja las tenía rematadas Montalbán. Según el Informe de Gilberto de Bedoya de junio de 1587, en la torre de Marijata se había ejecutado la cimentación de cuatro varas y estaba subida cinco cuartas; la de Portechón tenía abierta una zanja de cinco varas y media; y la de Sierra Bermeja, la más avanzada, tenía construido un terrapleno de veinte pies de alto, es decir, 5,57 metros. ${ }^{86}$ En estas tres torres se habían invertido 1.590 .798 maravedíes. ¿Qué parte de este dinero se le debía a Luis de Montalbán?

Del mismo modo indica que está a la espera de recibir algunos dineros para empezar a levantar las torres del Río del Oro y la de Arenilla, obviando aquellas otras que tenía también rematadas a su favor en el litoral de Arenas Gordas: Carbonera, Higuera y Asperillo. Con esta escritura, Luis de Montalbán libera a sus fiadores, todos vecinos de la villa de Almonte, de una fianza de 6.000 ducados que le otorgaron en diciembre de 1588 para la construcción de aquellas seis torres, pero al mismo tiempo hace cesión de su remate en uno de sus fiadores, Diego Martín de Rioseco, que recibirá los dineros pendientes de cobro, los siguientes abonos para las obras y finalizará las torres. Por el tenor de la escritura, parece que Luis de Montalbán fue presionado por aquellos fiadores que le habían "pedido os saque de la dicha fianza, de manera que quedéis seguros $y$ sin riesgo alguno, y por no ser vecino de esta villa ni tener en ella ningunos bienes conocidos". La paralización de las obras de las torres y la sospecha de que Luis de Montalbán suspendía las obras pendientes, inquietaron a este grupo de hacendados almonteños.

\section{LA FINALIZACIÓN DE LAS TORRES Y SU MANTENIMIENTO.}

En nuevo comisionado real y juez de torres enviado por el Consejo de Justicia en 1595, Fernando Álvarez de Bohórquez, acabó a destajo en dos años y medio (1598) la mayoría de las torres que encontró empezadas en Arenas Gordas, Palos, Gibraleón y Ayamonte, dejando en manos de los señores jurisdiccionales otras comenzadas en sus respectivos términos y en los plazos establecidos en sus remates. ${ }^{87} \mathrm{Al}$ parecer, por el ańo de 1604 se sentenció el pleito que los pueblos y

86 Datos confirmados por la investigación reciente de Mira Toscano et. al., La torre de Sierra Bermeja ..., op. cit., pp. 26-27.

87 A.G.S., G. A., leg. 689. Consejo de Guerra de 31 de julio de 1608. En Mora-Figueroa, L. DE: Las torres de almenara ..., op. cit., pp. 112. 
señores nobiliarios entablaron con la Corona por la financiación de las torres, ${ }^{88}$ sentencia por la cual aquellos gastos correrían distribuidos por todos las ciudades, villas y lugares de la costa onubense "comprendidas dentro de las treinta leguas de las dichas torres y por los señores de vasallos respectivos". ${ }^{8}$

Por enero de 1607 llega a Andalucía un nuevo comisionado real, el licenciado Rodrigo Yáñez de Ovalle, también como juez de torres, con una doble misión. Por un lado, para que hiciese balance de lo ejecutado y gastado hasta el momento en las torres, el presupuesto para acabarlas todas y su futuro mantenimiento y dotación de hombres y armamento; por otro, estudiar el estado de la riqueza y población de aquellos pueblos incluidos en aquellas treinta leguas de la costa. Con ambos informes y el parecer personal de este juez, el Consejo de Guerra propondrá al Rey las mejores soluciones para finalizar este proyecto defensivo tan urgente y necesario como largamente interrumpido. ${ }^{90}$

Tenemos constancia de la llegada de este Juez a estas tierras onubenses por aquellas fechas, citando a la villa de Almonte en la de Palos, el sábado 13 de enero de 1607, para conocer su riqueza y número de vecinos:

En este cabildo se trató que a su merced el dicho alcalde Martín Pavón y a Bartolomé Martín, síndico procurador, le fue notificado un mandamiento del licenciado Rodrigo Yánes de Ovalle, juez de las torres de la costa de Andaluzía, en que manda que el tesorero del cabildo y otra persona del vayan a la villa de Palos a treze de este a llevar el libro de quentas y propios de este cabildo y fe de la vecindad y a estar presente a tomar treslado de los autos que hiziere y pague los salarios de su merced y sus oficiales. ${ }^{91}$

Tras esta visita, el juez comisionado informó al Consejo de Guerra del estado de las obras, la inversiones realizadas, el presupuesto para acabar las obras de las torres, dotarlas de personal y defensa artillera, total que consumiría unos 20 millones de maravedíes. Para el futuro mantenimiento completo de estas defensas costeras, proponía un impuesto directo o sisa sobre la extracción de pescado fresco y salado. ${ }^{92}$ Este impuesto se le conocería en Almonte como "renta del derecho de las torres" y perduraría hasta finales del siglo XVIII. Esta sisa

88 Mira Toscano el Al., "La torre de Sierra Bermeja ..., op. cit., p. 28.

89 A.G.S., G. A., leg. 689. Consejo de Guerra de 31 de julio de 1608. En Mora-Figueroa, Las torres de almenara ..., op. cit., pp. 112.

90 Ibídem.

91 A.M.A., leg. 3. A. C. de 11 de enero de 1607.

92 Ya en aquel Consejo de Guerra de 31 de julio de 1608 se proponía un impuesto de 17 maravedíes y otro de 12 maravedíes, pero no se indica sobre que peso o cantidad de pescado. 


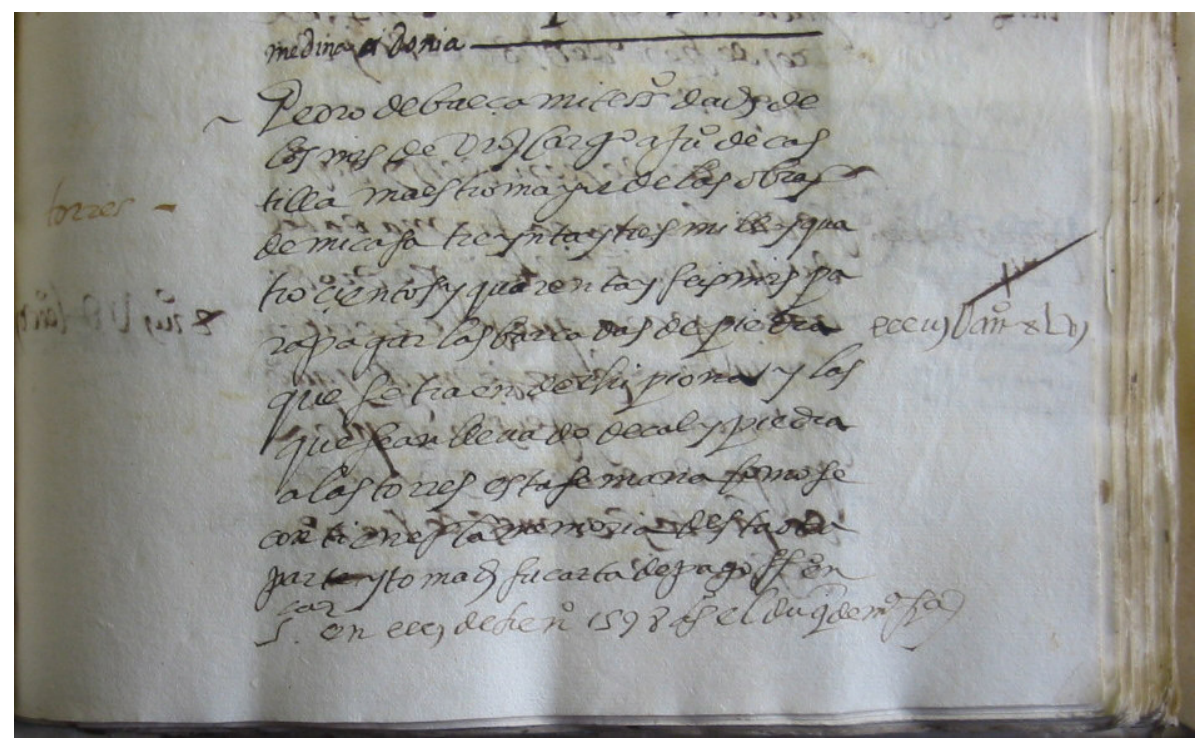

Reproducción fotográfica de asiento contable relativo a los gastos de acarreo de piedras y cal para las torres (Arenas Gordas). 31 de enero de 1598. A.F.C.M.S., leg. 895. Cortesía de la Fundación Archivo Casa Medina Sidonia.

real en Almonte parece que importaba dos maravedíes la libra de pescado $^{93}$ y su recaudación se llevaba a cabo a través de un "Fiel receptor de las Torres" que nombraba cada año el Ayuntamiento; Fiel que a su vez rendía cuentas, también anualmente, ante el Administrador de la Renta de las Torres del reino de Sevilla. El importe de la recaudación del año 1712 por este concepto, 55 reales, ${ }^{94}$ nos puede dar una aproximación del volumen de pescado capturado en el litoral almonteño: 430 kilos; volumen que nos parece muy poco fiable de las capturas reales que se podían producir en las pesquerías almonteñas desde Zalabar a Río de Oro en esas fechas tempranas del XVIII, ya que el régimen recaudatorio del fielato suponía que un porcentaje de la sisa cobrada fuese la remuneración del fiel. Aunque no se especifica, puede que aquella cantidad haga referencia a uno de los diversos asentamientos pesqueros de Arenas Gordas y no a todos los existentes.

Por el año de 1608 se encontraban finalizadas las obras de las torres de Río del Oro, La Arenilla, Punta Umbría, Marijata, El Terrón, Catalán e Isla Canela,

93 A.M.A., leg. 5. A. C. de 31 de diciembre de 1668. Único dato que hemos encontrado. En este acuerdo también se menciona otro "Fiel Receptor de los 16 maravedies en libra del pescado", pero parece que es un impuesto municipal.

94 A.M.A., leg. 7. A. C. de 28 de diciembre de 1712. 
pero no estaban artilladas y sin torreros. Quedaban aún por terminar las torres de Morla, Asperillo, La Higuera, Carbonero y Cruz de Zalabar. Las seis torres de Arenas Gordas las finalizó el duque de Medina Sidonia, para cuyo fin solicitó un préstamo a particulares de 18.000 ducados (6.732.000 maravedíes) sobre sus rentas, obteniendo las preceptivas licencias reales en San Lorenzo el 30 de julio de 1597 y en Madrid en 29 de junio de 1598. ${ }^{95}$ Pero, al parecer, cuando la tesorería ducal cerró las cuentas de las inversiones en estas torres el año de 1622, resultó un gasto total de 18.752 .166 maravedíes. ${ }^{96}$

Por fin, aparecen todas finalizadas por el ańo de 1618, salvo la de Asperillo, según informe presentado en 25 de mayo al Consejo de Guerra por el capitán Cristóbal Mejía Bocanegra, nuevo y último Juez de Torres enviado a Andalucía. ${ }^{77}$ La de Asperillo quedó concluida por el año de $1622 .{ }^{98}$

\section{Conclusiones}

El proyecto de un sistema de vigilancia y defensivo en las costas de la Andalucía atlántica mediante la erección de una serie de torres vigías, estuvo plenamente justificado por la presencia continuada de flotillas corsarias, norteafricanas y europeas, que entorpecían el comercio en todo el golfo de Cádiz, el paso de la Flota de Indias e infligían un daño muy doloroso a los asentamientos pesqueros jabegueros, con su negocio de redención de cautivos; sin olvidar los saqueos cometidos en núcleos urbanos, algunos tan importantes como el de Cádiz. En el espacio de Arenas Gordas, la mayoría de los emplazamientos de las torres coincidieron sabiamente con estas pesquerías: Carboneros, Higuera, Asperillo y Río del Oro, principales abastecedores de pescado de Sevilla, Huelva, Extremadura e incluso Madrid, ciudad y Corte donde llegaban los atunes de Carboneros en salmuera. Sólo el baluarte de Zalabar tenía funciones defensivas de la entrada del río Guadalquivir.

La documentación inédita que aportamos sobre el ingeniero cordobés Luis de Montalbán, aparte de dilucidar y aclarar algunas dudas en la historiografía de este proyecto de torres vigías, nos aproxima a una historia personal de un hombre que apostó desde el primer momento por aquel proyecto militar, sin menoscabar su interés profesional y económico en unas obras que en 1608 habían consumido 42 millones de maravedíes, ${ }^{99}$ y al que estuvo ligado durante

95 A.F.C.M.S., leg. 2.761.

96 A.F.C.M.S., leg. 900. "Certificación y testimonio de los gastos de las torres de Arenas Gordas".

97 A.G.S., G.A., Sección Guerra y Marina, leg. 819, en Villegas martín et al.: "Nuevas aportaciones ..., op. cit., pp. 123-126.

98 A.F.C.M.S., leg. 895. "Asiento de las cuentas de los portes que se hicieron para las torres de Arenas Gordas, 1590-1622”.

99 Consejo de Guerra de 28 de noviembre de 1606. A.G.S, G.A., Leg. 689, en Mora-figueroa, 
tres lustros, pero al que definitivamente tuvo que abandonar ante la ineficacia de unos jueces y directores del proyecto que no solucionaron el principal problema de financiación del que fuera considerado uno de los programas defensivos mas importantes de Felipe II. Luis de Montalbán intervino en la primera visita del comisionado Bravo de Lagunas y del ingeniero Livadote, llevó en mano a la Corte los emplazamientos y trazas de las torres, acompañó al ingeniero y hermano Francisco, viejo y enfermo, como director del proyecto durante dos años, se convirtió en contratista de las propias torres y sobrevivió a los reveses de las paralizaciones como tratante de carbón y corambre en la villa de Almonte. Finalmente, casi arruinado y acosado por avalistas y el gobierno de Almonte, vende sus bienes en esta villa, liquida cuentas y deudas y parte definitivamente de Almonte por abril del año 1596. Un verdadero paradigma de las vicisitudes por las que atravesó el más importante proyecto militar de Andalucía en el tránsito de los siglos XVI-XVII.

Estas defensas finalmente concluyeron hacia 1622, aunque con cuatro decenios de retraso. Los gastos de mantenimiento de las obras, personal y artillería recaerían sobre los armadores de las pesquerías del litoral onubense, a través de un nuevo impuesto directo o sisa sobre el pescado fresco y salado obtenido en aquellas playas. A pesar de la erección y dotación militar de aquellas torres, los pescadores de la costa de Arenas Gordas y de todo el resto de litoral onubense, continuaron sin trabajar en paz, con el miedo cotidiano a ser apresados en cualquier hora del día por los temibles "moros", como llegó a suceder en los siglos XVII y XVIII. ${ }^{100}$

\section{ApÉNDICE DOCUMENTAL.}

A.P.N.L.P.C., legajo 7, fotogramas 273-278. Escritura de obligación de varios vecinos de la villa de Almonte a favor de Luis de Montalbán, vecino de Almonte, y rematista para la construcción de seis torres en Arenas Gordas, Arenilla y Cabeza Seca en las costas de Andalucía, ante el E. P. Diego Dávila. Fecha en la villa de Almonte en 12 de septiembre de 1588.

Sepan cuantos esta carta vieren como nos Fernando Pinto, Pedro Bejerano, escribano; Juan Martín Abad, Ocasio Alonso y Diego Martín de Rioseco, vecinos

Las torres de almenara ..., op. cit., pp. 112-113.

100 A.P.N.L.P.C., leg. 49, fotogramas 302-303. Escritura de obligación de dar y pagar por el alcalde del concejo de Almonte lo que costase la redención de los cautivos Alonso Casado, de más de 50 años, Alonso Martín, de menos de 40 años y de Juan Lozano, de más de 60 años, el día miércoles 18 de agosto de 1638 al convento de Ntra. Sra. de la Merced de Sevilla. Almonte, 1638. Escribanía de Juan Bautista Serrano. Le siguen otras escrituras relativas a cautivos a lo largo del siglo XVII. Para los años 1675-1677 hay una relación de cautivos apresados en Arenas Gordas en A.F.C.M.S., leg. 2.168. Para los siglos XVII y XVIII, vid. Gozálvez escobar, "La piratería y la redención de cautivos ..., op. cit. 
que somos de esta villa de Almonte, todos cinco juntamente de mancomún y a voz de uno y cada uno de nos, por sí y por el todo, renunciando como renunciamos las leyes de duobus reys de vendi y la auténtica presente codicefi de insoribus y el beneficio de la división y escarsión y todas las otras leyes, fueros y derechos que son y hablan en razón de la mancomunidad como en ellas se contiene; decimos que por cuanto en Luis de Montalbán, vecino de esta villa, se remataron de último remate como el mayor ponedor el edificio y hechura de seis torres en la costa de Arenas Gordas, Arenilla y Cabeza Seca por cierto precio de maravedíes contenido en los remates que sobre ello pasaron en la villa de Huelva ante Andrés Martín, escribano público de ella, a que nos referimos, e con ciertas condiciones, el tenor de los cuales es este que se sigue:

1. Es a condición que el maestro o maestros que se encargaren de cada una de ellas sea obligado a estas condiciones. Que ha de abrir el cimiento en diámetro y de cuarenta tercias en circunferencia y la ha de abrir hasta hallar buen firme y no hallando firme y el agua no diere lugar entre lugar sea obligado en todo este sitio de echar muchas estacas de pino verde a su costa, con que se de licencia donde pueda al más cercano monte cortarlas para la dicha obra.

2. Y es condición que las dichas estacas sean de hincar una tercia de una a otra todas y gradualmente por un nivel y estando a nivel ha de tomar el agua con cal y arena de la gorda, y ha de labrar toda esta zanja de piedra y cal hasta sacarla para hacerla tierra y una vara más alto de buena obra.

3. Y con condición que estando a nivel esta dicha obra a de formar la muralla de trece pies de grueso y hecho que son veinte seis de suerte que han de quedar dos pies de agua en circunferencia, como dicho es.

4. Y con condición que estando la dicha obra en el dicho peso y nivel la ha de subir veinte pies a lo más alto de tierra a plomo y suba esta obra por la parte de dentro a plomo dejando algunas piedras salidas para la trabazón de la tierra a plomo, y por la parte de fuera a traluz hasta los dichos veinte pies de alto donde se ha de formar puertas y caracol como se dirá y que el dicho terrapleno ha de subir con esta dicha muralla a dos tragas y pasas y manteado con su agua y alguna cal hasta los dichos veinte pies.

5. Y es condición que estando en lo más alto del terrapleno ha de formar la dicha muralla y fabrica de diez pies de grueso, y en la redonda forme una puerta en la parte de tierra de ancho de dos tercias y media y de alto cuatro y por la parte de dentro forme un caracol de ancho de dos pies y medio y los escalones han de ser de una piedra entera y de alto han de tener una tercia y vaya subiendo el dicho caracol y gradualmente en la dicha obra.

6. Y con condición que estando esta muralla de once pies de altura dedenpelar (sic) a volver una bóveda de medio punto y de grueso de un ladrillo bien cocido y fuerte, y las enjutas de esta dicha bóveda vayan labradas de derretidos hasta igualar con la llave y encima le han de echar un suelo de una tercia bien pisado, 
y la entrada de este suelo ha de tener una puerta de caracol con su puerta fuerte.

7. Y con condición que la primera bóveda en todo igual suba y prosiga la muralla del mismo grueso guardando de dentro y altura biel [sic] fuera hasta lo más alto de la torre que son sesenta pies y en todo a los once pies donde empieza a volver la segunda bóveda de grueso de dos ladrillos y labrarlas enjutas de derretidos como dicho es de la caracola de ir subiendo gradualmente hasta lo alto de la torre haciéndole su bóveda de cubierta.

8. Y con condición que estando lo más alto de esta bóveda y a nivel toda esta fábrica se ha de echar un ardón de piedra labrada a cordel y que tenga de grueso una tercia y vuele media tercia y se ha de echar un suelo de hormigón mezclado a tres de cal e una de cascajo echado por sus tongas bien pisado y bruńido para que resista el agua y han de formar encima de este ardón y suelo un antepecho de grueso de una vara por la parte de adentro de alto y por la parte de fuera en esta redonda a de remar un palmo más alto del ardón por la parte de la mar; en la parte de tierra debe ser de más altura conforme a la disposición de la tierra.

9. Y con condición que estando en lo alto del terrado a plomo de la puerta a de formar y dejar para la defensa de la puerta un ladrón que tenga poco menos de media vara de hueco y una vara de largo y de alto conforme [ilegible] tuviere el antepecho que se le señalare adelante como dicho es para la defensa de la barranca que al presente se puede.

10. Y con condición que la puerta que han de echar en la dicha torre ha de ser de un tablón grueso y fuerte guarnecido con hoza de hierro bien claveteada y su cerradura fuerte y por de dentro cerrar en el grueso de la muralla una tranca fuerte en su caja que pase de una parte a otra, la cual puerta ha de tener en lo alto de ella una bóveda de medio punto de ladrillo y de piedra y vaya capillado por la parte de dentro y ha de tener la puerta una barra de hierro por de dentro para asir en ella una escala de cuerda.

11. Y con condición que el caracol dicho que ha de llevar esta fábrica ha de formarse por la parte de dentro hacia la parte de tierra junto a la puerta y vaya labrado como dicho es hasta lo más alto de la dicha fábrica.

12. Y con condición que las tapias de estas fábricas han de tener seis pies de largo y tres pies de grueso y tres pies de alto, midiendo sus copormacias (sic); y se entiende el caracol, paretas, alteral y ladrón y bóveda de donde capillan a retumbar que se entiende el medio punto.

13. Y con condición que el terrapleno arriba dicho le han de hacer de cal y arena en el todo lo mejor que se hallare y pisado a pisón por sus tongas echándole su agua el cual terrapleno a de ir subiendo conforme a la práctica.

14. Y con condición que todas estas fábricas desde el cimiento hasta lo más alto y acabadas de toda perfección han de ser de buena piedra y de buena cal y arena y agua dulce bien trabada y bien ripiada echándole su agua como lo requiere y el tiempo lo pidiere, de suerte que vayan todas revocadas por de 
dentro y fueren y acabarlas como semejantes obras se requieren y lo son y serán estas dichas obras, han de ir mezcladas una de cal y otra de arena que es a la mejor que se hallare en la dicha costa con espuertas iguales, todo a contento de Juan Pedro a cuyo cargo están la dicha fabrica de las torres del Andalucía por el Rey nuestro señor.

15. Y con condición que el maestro en quien se remataron a de estar obligado a dar todos los materiales necesarios y carne y cuero de la dicha obra y no se le ha de dar más de solamente los maravedíes en que se le rematare y se le dará favor y ayuda para que pueda sacar los materiales necesarios para la dicha obra donde quisiere sin perjuicio de parte de cualquier maestro; ha de dar fianzas llanas y abonadas a contento de Juan Pedro con autoridad de la justicia ante mi el presente escribano, y dadas las dichas fianzas de que hará las dichas obras dentro de año y medio dicho desde el día que se recibiere dineros se le darán luego dos mil ducados para en cuenta de las dichas seis torres; y estando sacadas y subidas una vara alto del suelo de la tierra se le dará otros dos mil ducados y como fuere labrando se le irá concediendo dineros hasta que acabe la dicha obra, y acabada se le medirá y pagará todo lo que se le debiese; y empezada la dicha obra no ha de alzar mano de ella hasta haberla acabado.

16. Y con condición que rematadas las dichas obras en el dicho maestro y no dando fianzas dentro de diez días primeros siguientes sea obligado a pagar las bajas que hubiere y así vaya sucesivamente en todos los ponedores, más cien maravedíes a los oficiales que atrás vinieren.

17. $Y$ es condición que en el tal sitio a de haber un zanja de sesenta pies en diámetro y en circunferencia y la ha de ahondar hasta hallar buen firme como se requiere a tal obra y caso que no halle tan buen firme como se requiere y no dando lugar el agua a más fin que en todo este sitio muchas estacas de pino verde hincadas todo lo que se pudiere de suerte que den todas las cabezas iguales y a nivel y una tercia una de otra y tomada y engarzada entre otra de buena piedra y cal y suba labrando y siguiendo esta dicha zanja de cal y arena y piedra hasta una vara más alto de su perfección de la tierra y esto a nivel esta zanja llena y labrada como dicho es.

18. Es condición que ha de formar de dieciocho pies en circunferencia de suerte que dé dos pies de cepa igual en todas partes y así subiendo hasta los veinte pies de altura que es lo más último de terrapleno, y este dicho terrapleno ha de subir como va subiendo en fábrica pisada e incorporada con la dicha fábrica con su cal, tierra y cascajo por sus tonsas bien prensado, y los dichos dieciocho pies de grueso vaya labrado por la parte de dentro a plomo sacado trabazón para entrarse con el terrapleno por la parte de fuera vaya en comenzando de los dichos dieciocho pies se halle a lo más alto del terrapleno donde se han de formar la puerta de quince pies de grueso y esta tal a de ir bien labrada a regla y a piedras juntas lo más que pudiere para la defensa del agua. 
19. Y es condición que en los más alto de este terrapleno se ha de hallar cincuenta pies de diámetro sea obligado ha echar en circunferencias de piedra junta y que vuele un cuarterón de alto una tercia y de allí forme el grueso de la muralla de quince pies de grueso donde por la parte de la tierra forme una puerta y un caracol que suba igual con la muralla.

20. Y es condición que la puerta ha de tener dos pies y medio de ancho y cinco pies de ancho [sic] dejando en la muralla su caja para la trona que ha de tener de ancho dos pies y medio y los escalones han de ser cada uno de una tercia entera y tenga de peralta una tercia y vaya subiendo igual como va subiendo la dicha muralla y la dicha puerta en todo a los cuatro pies ha de volver una bóveda de ladrillo o piedra y sea todo el grueso de la muralla a pie alzado que vaya a dar a donde y principio del caracol y va subiendo todo en circunferencia hasta donde ha de mover la primera bóveda que será de altura a los pies; y de allí empiece a mover la dicha bóveda de medio punto y tenga de grueso ladrillo y medio y que el ladrillo de esta bóveda y grueso de muralla vaya labrado igual hasta lo más alto de la llave, labrado todo de derretido de buena mezcla, y estando a nivel prosiga y labre esta muralla por la parte de dentro a plomo y subiendo todo el grueso de esta muralla como dicho hasta el principio de la segunda bóveda que está a los ocho pies del grueso, empiece y vuelva la segunda bóveda de grueso de dos ladrillos de peralta de buen ladrillo como dicho es, prosiga su muralla y enjutas bien labrada y bien ripiada, lo uno y lo otro hasta igualar con la llave de la dicha segunda bóveda estando a peso y a nivel eche un ardón a la redonda de piedra de una tercia de grueso que vuele media tercia, y que estas dichas piedras vayan trabadas por la parte de dentro tengan una vara de lecho.

21. Y es condición que en todo esta dicha obra y cara con subida al peso de este ardón forme y labre un antepecho por la parte de la mar de alto de una vara por la parte de dentro y otra vara de grueso y por la parte de fuera desde el ardón suba una tercia a plomo y vaya rapante a lo más alto de la parte de dentro; este antepecho a la redonda a de ser de cantería labrada y encadenada una con otra para que la artillería no la pueda desbaratar.

22. Y es condición que el antepecho que cae en la parte de tierra sea obligado a hacerlo de altura que se le señalare a su tiempo conforme a la disposición de la tierra y lo mismo será el altura y apileo del caracol y con sus troneras en la parte que se le señalare.

23. Y es condición que estando todo esto en el dicho peso a lo más alto de esta bóveda y suelo de ella a de tener y echar un suelo de hormigón de media vara de grueso en medio y por los lados una tercia echado por sus tongas de suerte que le quede corriente por donde despida el agua por sus caños y troneras. Este hormigón ha de ser de un hormigón mezclado de casco y cal, ha de tener de cal tres espuertas y una de casco y echado y pisado por sus tongas de manera que vaya fuerte, firme y bien bruñido y con buena corriente para que la artillería y 
que el que estuviere no le ofenda.

24. Y es condición que encima de la puerta a lo alto de este terrado tenga un ladrón para poder defender la puerta de piedra labrada que tenga canes y sus canes y tenga de hueco media vara y por la parte de fuera para que el reparo de este ladrón tenga un antepecho de una tercia de grueso de piedra labrada y encadenada con su plomo y unas lanas descoro; tenga este ladrón de ancho de la puerta y el alto conforme a la disposición de las barrancas de la tierra que a su tiempo se dirá al hacer estos antepechos para que se hagan como convengan a la defensa de esta torre.

25. Y es condición que las medidas de esta obra se entiende que ha de tener cada una tapia de largo seis pies que son de dos varas y una vara de alto y otra de grueso, caracol y puerta hueco por macizo y la vuelta de la bóveda por la misma medida.

26. Y es condición que toda esta torre se ha de labrar de buena piedra y buena cal y buena arena gruesa y bien labrada, bien trabada y bien ripiada, echándole su agua como se requiere y el tiempo lo pidiere, de suerte que vaya todo como se conviene a semejantes obras.

27. Y es condición que las mezclas vayan mezcladas de la arena y cal y una de cal y otra de arena gorda y de la mejor que se hallare en los dichos sitios y sea mezclada y gastada con agua dulce; toda esta obra ha de ir revocada por de dentro y fuera y acabada en toda perfección, así lo uno como lo otro a contento de Juan Pedro a cuyo cargo están las dichas fábricas de toda la costa de la Andalucía por mandado del Rey nuestro señor con su real firma.

28. Y es condición que esta torre se ha de dar acabada como dicho es desde el día que recibiere los primeros dineros sin alzar mano de ella en año y medio como el tiempo diere lugar no faltándole dineros para ello.

29. Y es condición que se le ha de dar luego mil y quinientos ducados para que se pueda apercibir de muchos materiales y estando una vara del superficie del suelo le den otros mil ducados y a adelante como fuere labrando y se le hará enfajo [o ensayo] de lo que hubiere hecho y se le irá dando dineros de suerte que prosiga la dicha obra sin parar.

30. Y es condición no se le ha de dar más que solos los maravedíes en que se rematare y es condición que los oficiales se le ha de dar favor y licencia para poder sacar los materiales donde más cerca los hallare y bastimentos para la dicha obra pagándolos a justo precio de como valieren sin perjuicio de partes.

31. Y es condición que en quien se rematare esta dicha obra sea obligado a dar fianzas llanas y abonadas a contento del dicho Juan Pedro tomándole con autoridad de justicia y escribano real dentro de diez días del día que se rematare y señalaren Andrés Martín, escribano público.

Por ende otorgamos y conocemos que nos obligamos por esta carta que el dicho Luis de Montalbán hará y labrará las dichas seis torres según y de la 
forma y manera que se contiene en el dicho remate guardando, cumpliendo las dichas condiciones y cada una de ellas, donde nosotros todos cinco debajo de la dicha mancomunidad con los demás que sean y obligaren como sus fiadores y principales pagadores sin que contra el dicho Luis de Montalbán ni sus bienes sea hecha ni se haga excursión de bienes ni otra diligencia alguna aunque el derecho la conceda, haremos las dichas torres, cumpliremos las dichas condiciones como en ellas y en cada una de ellas se contiene; y si el dicho Luis de Montalbán o otra persona por él hubiere recibido algunos maravedíes para en cuenta de los edificios de las dichas torres lo pagaremos todo a la orden del dicho Juan Pedro, a cuyo cargo está el beneficio de las dichas torres y las demás de la costa de la Andalucía, con las costas y salarios y en las partes y lugares que el dicho Juan Pedro mandare y ordenare bien y cumplidamente sin pleito ni costas, [aparato legal] ... Fecha la carta en la villa de Almonte, lunes doce días del mes de diciembre de mil y quinientos y ochenta y ocho años, y los dichos otorgantes que yo el presente escribano doy fe que conozco, no lo firma el dicho Ocasio Alonso porque dijo que no sabe y a su ruego lo firmó por él y testigo uno de los testigos de esta carta en el registro con los dichos Fernando Pinto, Pedro Bejerano, Diego Martín y Juan Abad que saben escribir; fueron testigos presentes Melchor Rodríguez Mallar y Antón Martín, alguacil, y Juan Meléndez, carpintero, vecinos de esta villa. Va escrito y tachado: en estado donde decía/ de tierra/g/se le ha de dar más. Va escrito entre renglones: donde dice/con los demás que se obligaren. Valga todo y no valen pesca y no valga lo tratado.

Fernando Pinto [rubricado]. Pedro Bejerano [rubricado]. Antón Martín [rubricado]. Diego Martín [rubricado]. Diego Dávila, escribano público [rubricado]. Derechos tres reales. 
